This item was submitted to Loughborough's Research Repository by the author.

Items in Figshare are protected by copyright, with all rights reserved, unless otherwise indicated.

\title{
Combined numerical and experimental investigation of the micro- hydrodynamics of chevron-based textured patterns influencing conjunctional friction of sliding contacts
}

\section{PLEASE CITE THE PUBLISHED VERSION}

http://dx.doi.org/10.1177/1350650114559996

\section{PUBLISHER}

Sage (IMechE)

\section{VERSION}

VoR (Version of Record)

\section{PUBLISHER STATEMENT}

This work is made available according to the conditions of the Creative Commons Attribution 3.0 International (CC BY 3.0) licence. Full details of this licence are available at: http://creativecommons.org/licenses/ by/3.0/

\section{LICENCE}

CC BY 3.0

\section{REPOSITORY RECORD}

Morris, Nick, Michael Leighton, Miguel De la Cruz, Ramin Rahmani, Homer Rahnejat, and S.J. Howell-Smith. 2014. "Combined Numerical and Experimental Investigation of the Micro-hydrodynamics of Chevron-based Textured Patterns Influencing Conjunctional Friction of Sliding Contacts". Loughborough University. https://hdl.handle.net/2134/17147. 


\title{
Combined numerical and experimental investigation of the micro-hydrodynamics of chevron-based textured patterns influencing conjunctional friction of sliding contacts
}

Proc IMechE Part J:

J Engineering Tribology

20I5, Vol. 229(4) 316-335

(C) IMechE 2014

Reprints and permissions:

sagepub.co.uk/journalsPermissions.nav DOI: 10.1177//3506501/4559996

pij.sagepub.com

\author{
N Morris', M Leighton', M De la Cruz', R Rahmani', \\ H Rahnejat' and S Howell-Smith ${ }^{2}$
}

\begin{abstract}
Reciprocating and low-speed sliding contacts can experience increased friction because of solid boundary interactions. Use of surface texturing has been shown to mitigate undue boundary friction and improve energy efficiency. A combined numerical and experimental investigation is presented to ascertain the beneficial effect of pressure perturbation caused by micro-hydrodynamics of entrapped reservoirs of lubricant in cavities of textured forms as well as improved microwedge flow. The results show good agreement between numerical predictions and experimental measurements using a precision sliding rig with a floating bed-plate. Results show that the texture pattern and distribution can be optimised for given conditions, dependent on the intended application under laboratory conditions. The translation of the same into practical in-field applications must be carried out in conjunction with the cost of fabrication and perceived economic gain. This means that near optimal conditions may suffice for most application areas and in practice lesser benefits may accrue than that obtained under ideal laboratory conditions.
\end{abstract}

\section{Keywords \\ Laser surface texturing, chevron features, mixed regime of lubrication, micro-hydrodynamics, friction}

Date received: 30 January 20I4; accepted: 23 October 2014

\section{Introduction}

Energy efficiency is progressively viewed as the most essential attribute for all machines and mechanisms. An important source of energy inefficiency is friction, which may be viewed as an energy sink. Therefore, except for some occasions where friction is crucial for fulfilling certain functions, such as in traction, braking or locomotion, its minimisation is an important design goal. The increasing scarcity of fossil fuels with the associated increase in cost and their adverse effect on the environment are key motivators in the drive to mitigate the effects of friction.

As friction occurs naturally, there have been many attempts since antiquity to minimise the required effort to overcome it, as well as forming an understanding of it. Amontons ${ }^{1}$ described the underlying mechanism of friction as the interaction of rough surfaces, independent of their apparent area of contact. Later Euler ${ }^{2}$ provided the first definition for the coefficient of friction and its relation to the state of motion. Coulomb ${ }^{3}$ confirmed the findings of
Amontons and Euler in distinguishing between static and kinetic states of friction.

The Amontons-Coulomb fundamental laws imply friction as an inherent property of surfaces; their topography and mechanical properties. However, by the turn of the 20th century it became clear that these fundamental laws do not apply to real surfaces which are invariably wetted either by an applied film of lubricant or their contact tribo-chemistry leads to the formation of an oxide surface layer when exposed to normal atmosphere. ${ }^{4,5}$ In fact, nature itself has made use of rough surface topography in the presence of a fluid to enhance load-carrying capacity and also reduce friction. One example is the combined action

\footnotetext{
'Wolfson School of Mechanical and Manufacturing Engineering, Loughborough University, Loughborough, UK

${ }^{2}$ Capricorn Automotive Ltd., Basingstoke, Hampshire, UK

\section{Corresponding author:}

$\mathrm{H}$ Rahnejat, Wolfson School of Mechanical and Manufacturing Engineering, Loughborough University, Loughborough, UK. Email: h.rahnejat@lboro.ac.uk
} 
of fairly rough cartilage covered surfaces and synovial fluid in the endo-articular joints of all vertebrates through the mechanism of micro-elastohydrodynamic lubrication. ${ }^{6}$ Therefore, nature's own choice seems to run contrary to Amontons-Coulomb laws of friction. The perspective appears to be that of surfacelubricant as a system.

At the diminutive physical scale of surface asperities, boundary-active fluid species can adsorb to surface features, as well as being entrapped and entrained into the asperities' interspatial valleys. ${ }^{7,8}$ Therefore, unlike the idealised dry friction, wet rough contacting surface topography can actually aid lubrication and reduce friction. The realisation of this point has gradually led to the introduction of engineered textured features on sliding surfaces. In fact, the use of various surface texture forms has been shown to improve tribological performance in Costa and Hutchings, Etsion and Burstein ${ }^{10}$ and Ronen et al. ${ }^{11}$ among others. Numerical and analytical analyses have also led to the determination of 'optimal' texture form, geometry and distribution for sliding contacts, for example by Rahmani et al. ${ }^{12,13}$

The introduction of surface textures is most effective in circumstances when poor contact kinematics such as stop-start, reciprocating motion or low relative surface speed leads to lack of lubricant entrainment into the contact. These circumstances lead to boundary regime of lubrication. There are many such instances in various machines. For example, in internal combustion engines, piston motion reversals at top and bottom dead centres are accompanied by the momentary cessation of lubricant entrainment into the piston skirt and ring pack. Use of surface texturing, introduced in the vicinity of piston reversals, has shown to reduce frictional power loss, both analytically, ${ }^{14}$ as well as through testing by Etsion ${ }^{15}$ and combined studies by Rahnejat et al. ${ }^{16}$ Other investigations include that of $\mathrm{Yu}$ et al. $^{17}$ for the effect of texturing during sudden changes of speed in mechanical face seals and that of Pettersson and Jacobson $^{18}$ for reciprocating ring/roller contact in hydraulic motors. It is suggested that the cavities formed by the introduced micro-structures can act as lubricant reservoirs or encourage micro-wedge effect (micro-hydrodynamics) for lubricant entrainment. ${ }^{15,16,19,20}$ The micro-hydrodynamic effect is analogous to the pressure perturbations in natural mammalian joints, ${ }^{6}$ which improve the contact loadcarrying capacity. ${ }^{13}$ In fact, aside from this localised effect, surface textures have also been shown to expand the region in which hydrodynamic lubrication occurs. $^{21}$

The geometric form and distribution of texture features have also been investigated by many authors. The form largely depends on the method of manufacture/fabrication such as vibro-rolling, ${ }^{22}$ ion reactive etching, indentation, ${ }^{23,24}$ abrasive jet machining, ${ }^{25}$ photo-lithography, ${ }^{26}$ anisotropic etching ${ }^{26}$ and laser surface texturing (LST), ${ }^{15,16,27,28}$ the last of which has gradually become the process of choice. This is because LST lends itself to a greater degree of automation as well as a better control for application to curved surfaces such as cylinder liners ${ }^{16}$ and piston ring face-width, ${ }^{29}$ as well as fabrication of different texture geometries. Ryk et al. ${ }^{29}$ introduced partial texturing on the compression ring's flat chamfered facewidth, noting this to be the most effective in reduction of friction in their engine tests. On the other hand, Howell-Smith et al. $^{30}$ noted that whilst texture features can act as reservoirs of lubricant and aid reduction of friction, they may also cause oil loss in piston cylinder system as well as breach the sealing function of the compression ring. This suggests that it is better to introduce these features on the stationary cylinder bore/liner in the vicinity of the top ring reversal. Their results show that indented liners with features resembling the cross section of a Vickers tool provide optimum performance in a high performance fired engine. However, laser-etched crescent shapes (analogous to a chevron) are more practical and cost effective to produce on curved concave surfaces and perform nearly as well as the indented features. Costa and Hutchings ${ }^{9}$ also investigated a range of surface texture shapes, including chevrons under sliding conditions, where the largest improvement in generation of a hydrodynamic film was observed.

The current study combines numerical analysis and experimental measurement of chevron-shaped surface textures under sliding conditions. A numerical parametric study of the chevron shape design has been carried out, using improved chevron textures and distribution. The results are validated experimentally with the use of a reciprocating precision sliding bench-top test rig. The aims of the investigation are two-fold; firstly to further the fundamental knowledge of surface texturing and secondly, to demonstrate the design and development process for a suitable surface texture which can be used in real engineering applications.

\section{Reciprocating sliding contact}

Reciprocating or low-speed sliding contacts are subject to a transient regime of lubrication. Poor tribological conditions invariably occur at contact reversals, where lack of any relative sliding motion of the mating surfaces results in the momentary cessation of lubricant entrainment into the contact zone. This leads progressively to a greater number of ubiquitous asperities on the counterfaces coming into contact, leading to mixed or boundary regimes of lubrication. Such conditions are quite prevalent in many forms of contact, such as piston-cylinder system. ${ }^{31}$ Sliding contacts operating in the mixed or boundary regimes of lubrication experience increased frictional power loss when compared to fluid regimes of lubrication such as hydrodynamics, thus the reason 
for the various applications of texturing to the contiguous surfaces, ${ }^{14-16}$ all of which have shown $2-4 \%$ reduction in in-cylinder frictional losses, ascertained through improved BMEP. A more direct method of measurement would be preferred as well as linking any reduction in friction to the prevailing regime of lubrication. A direct in situ method of measurement for cylinder applications has been through the use of a floating liner, which is dragged by the reciprocating piston relative to the bore surface by an infinitesimal amount. The floating liner is flexibly mounted to the cylinder bore through intervening load cells which directly measure friction. Such arrangements have been reported by Furuhama and Sasaki ${ }^{32}$ and Gore et al. ${ }^{33}$ for engine testing conditions, although not including surface textures. However, friction in the engine cylinder is dependent on the many physical interactions arising from variations in the combustion chamber pressure, heat generation and thermo-elastic deformation of contiguous solids. Therefore, a fundamental scientific study is preferred to focus on the effect of surface texturing under controlled laboratory conditions, at least in the first instance, prior to engine applications. Hence, development of a precision reciprocating slider on a floating base-plate analogous to a floating cylinder liner would be advantageous. The focus of this study is mixed lubrication conditions at low sliding speed, whilst traversing a textured region. These conditions were noted for the engine case in Rahnejat et al., ${ }^{16}$ where the textured area was provided at the top compression ring reversal point.

A reciprocating slider bench test rig has been developed and described by Chong and De la Cruz et al. ${ }^{34}$ (Figure 1). A sliding thin strip slider with a face-width profile, representative of an engine compression ring is loaded against the flat plate, with a thin layer of lubricant applied. The plate is mounted upon precision, low friction bearings and is allowed to float, when dragged by the sliding strip. An electric motor is directly coupled to the loaded sliding strip via a low friction and almost backlash-free lead-screw drive. Piezo-resistive force sensors, positioned at either ends of the plate directly measure the inertial force of the floating plate, which is due to the generated contact friction as

$$
\sum F=-f_{t}=m a
$$

Short run times and suitable intervals are implemented to ensure repeatable testing conditions (See Appendix 2). A rotational laser Doppler vibrometer is used to record the actual speed of the sliding strip and a base oil is selected to lubricate the contact. This is a Grade 3 base stock (highly paraffinic with ultra-low sulphur content, with a viscosity index, $\mathrm{VI}>125$ ). No boundary active lubricant species are used in the base oil, as these would adsorb to the surfaces and form an ultra-thin low shear strength film, which would affect the repeatability of the experimental work. Further data for the base oil are listed in Table 1.

The thin strip is made of martensitic AISI $440 \mathrm{C}$ stainless steel hardened to $62 \mathrm{HRC}$. The flat plate is made of 150M19 (EN 14) carbon manganese steel, electroplated with a $140 \mu \mathrm{m}$ thick nickel-based coating containing co-deposited silicon carbide particulate (Ni-SiC). This coating is the choice for many cylinder liners of high performance race engines. The surface is then ground and polished. The corresponding data is given in Table 2.

\section{Laser surface texturing}

Chevron-shaped textures were laser etched onto a region of the floating plate as shown in Figure 2. A SPI 50 Watt fibre laser was used to create the chevrons. The laser parameters are provided in Table 3 .

After the LST process, the plate is polished for a short period of time to remove any residual splatter or debris protruding from the surface. Figure 3 shows an image of typical laser-etched chevrons obtained through the Alicona infinite focus microscope with a measurement resolution of $1 \mathrm{~nm}$.

The surface roughness of the plate and the flat ring were measured (Table 2), as well as the chevron depth and the sliding strip's face profile. The chevrons have a thickness-to-depth ratio of 0.11 (representative of an optimised ratio as demonstrated by Etsion and Sher ${ }^{28}$ ), although some variation in the chevron depth is produced in the LST process.

The LST produces chevrons with a cross-sectional profile similar to that of a parabola (Figure 3), and are therefore, modelled accordingly.

\section{Numerical analysis}

Prior to laser texturing of any form, geometry and distribution of chevron-type textures onto the surface of the sliding plate, it is important to undertake numerical analysis of the contact. This is due to the fact that there can be numerous combinations of geometrical parameters and distribution patterns with different outcomes. Therefore, the numerical analysis can provide the range of values that it is expected to yield desired performance from the textured surface. This can be carried out at low cost in comparison to the manufacture of a sufficiently varied set of samples. Then, a parametric study can be undertaken to strive to optimise the texture pattern and form with respect to minimisation of friction. A limited number of cases, advised through numerical simulation, can then be physically tested.

\section{Numerical method}

The reciprocating sliding contact is subjected to a transient regime of lubrication. Lubricant is entrained 


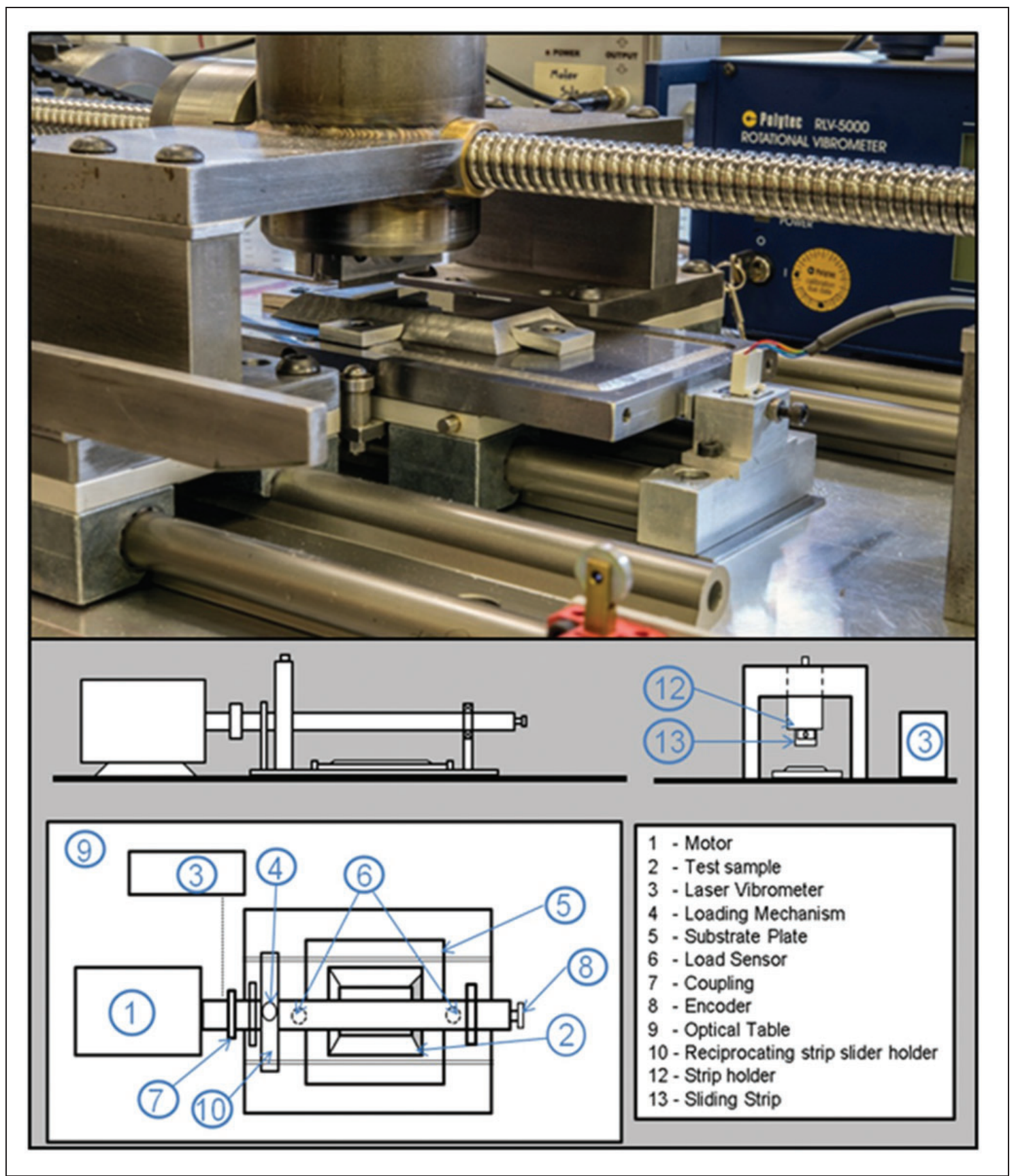

Figure I. The reciprocating slider test rig.

Table I. Base oil data.

\begin{tabular}{lll}
\hline Parameter & Value & Unit \\
\hline Eyring shear stress $\left(\tau_{0}\right)$ & 2 & $\mathrm{MPa}$ \\
Lubricant density $\left(\rho_{0}\right)$ & 839.3 at $20^{\circ} \mathrm{C}$ & $\mathrm{kg} / \mathrm{m}^{3}$ \\
Lubricant dynamic viscosity $\left(\eta_{0}\right)$ & 0.1583 at $20^{\circ} \mathrm{C}$ & $\mathrm{Pa} . \mathrm{s}$ \\
Viscosity-pressure coefficient $\left(\alpha_{0}\right)$ & $\mathrm{I} \times 10^{-8}$ & $\mathrm{~m}^{2} / \mathrm{N}$ \\
\hline
\end{tabular}

into the gap between the slider and the floating plate through the hydrodynamic wedge effect and carries the net contact load. At low speed of entraining motion or with cessation of sliding at or in the vicinity of motion reversal, there is insufficient film thickness. The film can then be interrupted by the interaction of counterface asperities, which also carry a small portion of the applied load, but contribute disproportionately to the generated friction. To obtain the hydrodynamic load-carrying capacity, the generated hydrodynamic pressures are obtained through solution of Reynolds equation. Assuming no side leakage flow in the transverse direction along the length of the thin strip slider, Reynolds equation becomes

$$
\frac{\partial}{\partial x}\left(\frac{\rho h^{3}}{6 \eta} \frac{\partial p}{\partial x}\right)+\frac{d}{d y}\left(\frac{\rho h^{3}}{6 \eta} \frac{\partial p}{\partial y}\right)=\Delta U \frac{\partial}{\partial x}(\rho h)+2 \frac{\partial}{\partial t}(\rho h)
$$


Table 2. Strip and floating plate data.

\begin{tabular}{lll}
\hline Parameter & Value & Unit \\
\hline Stroke length & 80 & $\mathrm{~mm}$ \\
Mean sliding speed & 24.44 & $\mathrm{~mm} / \mathrm{s}$ \\
Strip roughness $\left(R_{a}, R_{q}\right)$ & $0.51 \mathrm{I}, 0.709$ & $\mu \mathrm{m}$ \\
Liner roughness $\left(R_{a}, R_{k}\right)$ & $0.172,0.105$ & $\mu \mathrm{m}$ \\
Strip face-width & $\mathrm{I}$ & $\mathrm{mm}$ \\
Load (experimental) & 12.4 & $\mathrm{~N}$ \\
Strip length (experimental) & 30 & $\mathrm{~mm}$ \\
Load (numerical) & 0.82 & $\mathrm{~N}$ \\
Strip length (numerical) & 2 & $\mathrm{~mm}$ \\
\hline
\end{tabular}

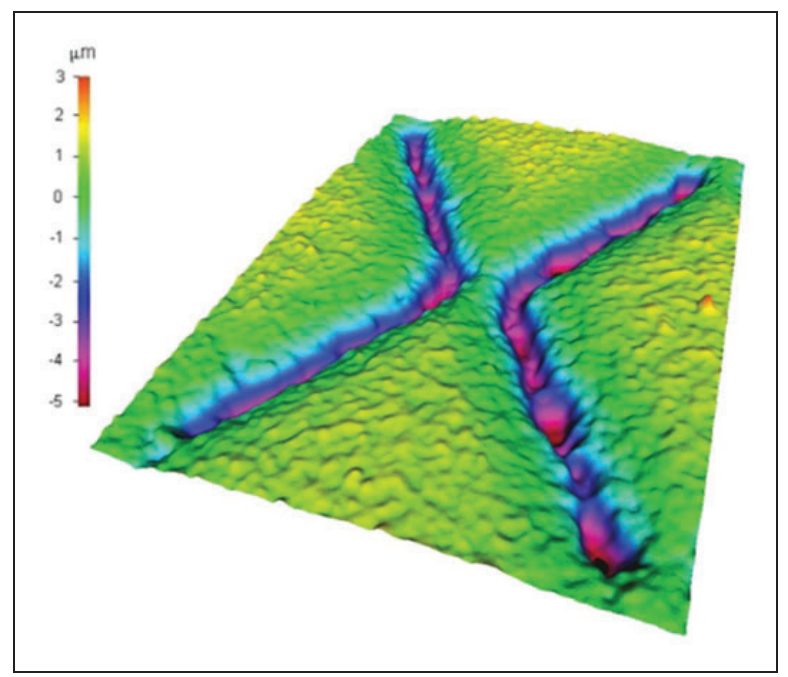

Figure 2. Measured 3D image of chevrons produced with the fibre laser.

Table 3. SPI fibre laser data.

\begin{tabular}{lll}
\hline Parameter & Value & Unit \\
\hline Beam width & 0.030 & $\mathrm{~mm}$ \\
Feed speed & 0.25 & $\mathrm{~mm} / \mathrm{s}$ \\
Pulse width & 0.500 & $\mathrm{~ms}$ \\
Frequency & 1687 & $\mathrm{~Hz}$ \\
Power & 12 & $\mathrm{~W}$ \\
Shielding gas & Nitrogen at 0.5 & $\mathrm{MPa}$ \\
Nozzle height & 0.1 & $\mathrm{~mm}$ \\
\hline
\end{tabular}

where $U$ is the sliding speed of the strip relative to the plate. The load applied (Table 2) is representative of the load intensity (load per unit length) for lightly loaded top ring in low sliding motion in the compression stroke prior to the TDC reversal for cylinders of $89 \mathrm{~mm}$ bore diameter with an assumed full circumferential conformance to the liner surface. A comparison of the load intensity between a fired engine and the reciprocating slider test rig is shown in Appendix 3. Under these conditions, reported by Akalin and
Newaz ${ }^{35}$ and Mishra et al. ${ }^{36}$ mixed regime of lubrication is prevalent with no localised deformation of surfaces.

A fully flooded inlet is assumed as the surface of the floating plate is provided with a layer of free surface film ahead of the sliding contact as shown in Figure 4. In the case of an engine, a starved inlet boundary can be encountered, particularly in the upstroke motion of the piston as a free surface film may not exist on the hot surface of the bore/liner.

The outlet boundary conditions are those of Swift $^{37}$-Stieber ${ }^{38}$ (Reynolds' exit boundary condition) with an assumed atmospheric vaporisation pressure of the lubricant at the film rupture point. The current boundary conditions do not take into account the effect of cavitation beyond the lubricant film rupture boundary. Cavitation can affect the load-carrying capacity of the contact. Elrod's ${ }^{39}$ cavitation method can be used instead of the Swift-Stieber boundary conditions to take this issue into account. This imposes continuity of Couette flow beyond the film rupture point. Even a better approach is to use a mass-conserving multi-phase approach with open exit boundary conditions such as that described by Ausas et al. ${ }^{40}$ who used this approach for the study of textured surfaces in journal bearings. They showed that cavitation plays an important role in loadcarrying capacity and generated friction. Shahmohamadi et al. ${ }^{41}$ also used this approach for the study of lubrication for piston compression rings but for untextured surfaces and with the inclusion of thermal effects. Shahmohamadi et al. showed that in the case of ring-bore contact, cavitation occurs mostly at mid-stroke piston positions where the results of their computational fluid dynamics analysis diverged from that with non-mass-conserving approaches. In a detailed study of various boundary conditions in piston compression ring conjunction, Arcoumanis et al. ${ }^{42}$ concluded that the Swift-Stieber boundary condition agreed better with their experimentally measure conditions. Based on these finding, the current analysis uses the Swift-Stieber exit boundary conditions. The inlet pressure at the front face of the strip is also set to the atmospheric pressure. Only a segment of the whole strip's width in the $y$-direction (direction of lubricant side-leakage) is included in the model to keep the computational time to an acceptable level. The applied load for the section of the contact considered for numerical analysis is shown in (Table 2). Hence, the computational boundary conditions are

$$
\begin{aligned}
& p=p_{\text {in }} \quad \text { at } \quad x=0 \\
& p=p_{c}, \quad \frac{d p}{d x}=0 \quad \text { at } \quad x=x_{c} \\
& \left.\frac{\partial p}{\partial y}\right|_{(x, 0)}=\left.\frac{\partial p}{\partial y}\right|_{(x, l)}=0
\end{aligned}
$$




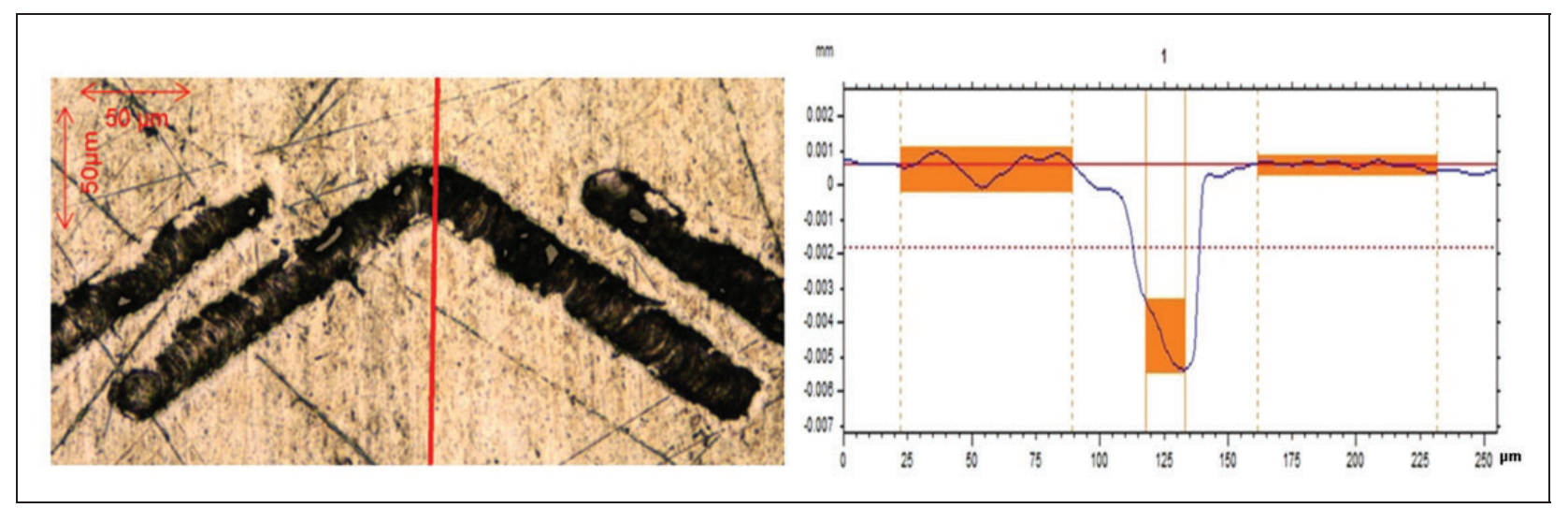

Figure 3. Image of a chevron and corresponding chevron depth profile.

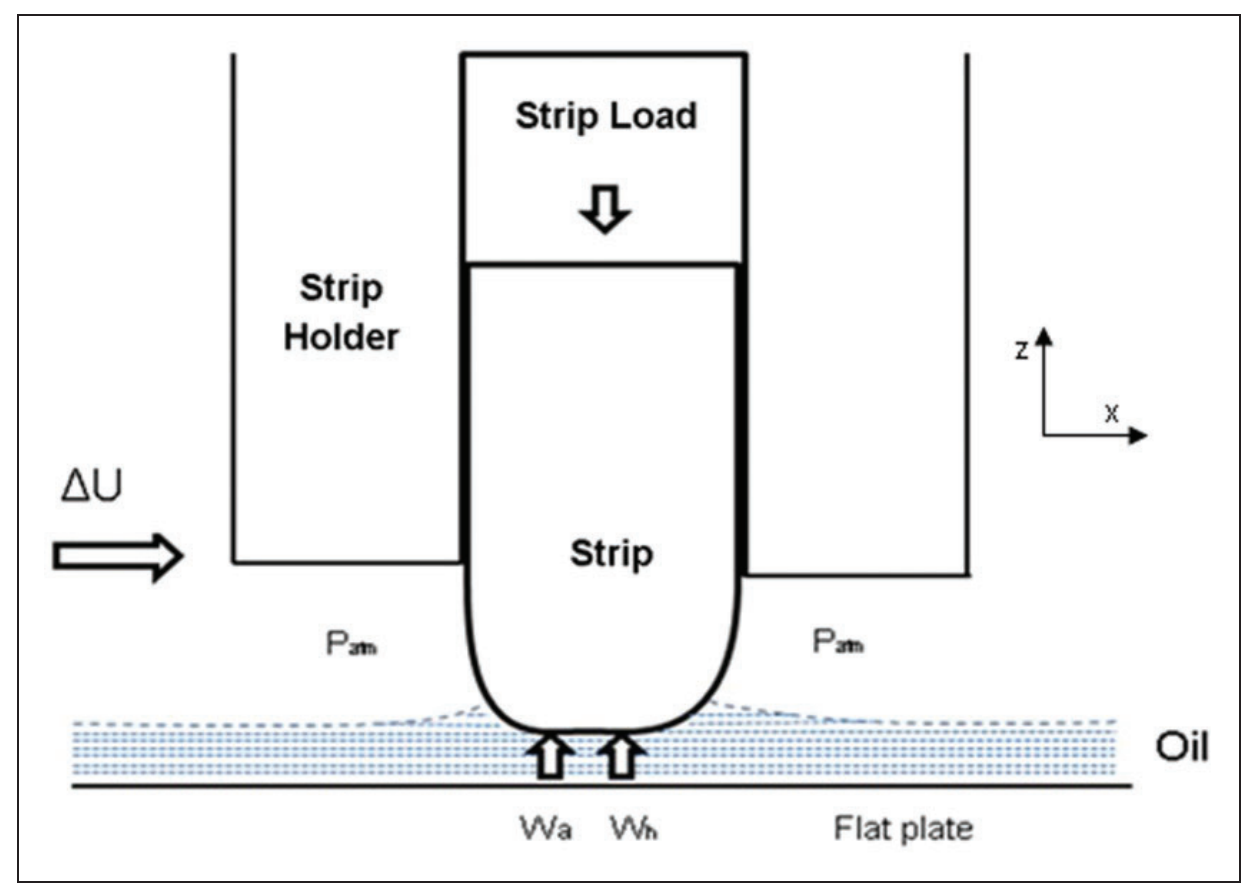

Figure 4. Contact configuration.

The generated pressures at such low loads are insufficient to induce significant piezo-viscous action of the lubricant. This is also noted by other investigators. $^{35,36}$ For completeness of the method, piezoviscous effects are retained. Furthermore, due to short testing times, isothermal analysis is undertaken at the laboratory temperature of $20^{\circ} \mathrm{C}$ as explained in the "Experimental results" section.

Therefore, for an isothermal solution only the piezo-viscous behaviour of the lubricant needs to be considered. According to Roelands ${ }^{43}$ where $p$ is the hydrodynamic pressure

$$
\eta=\eta_{0} \exp \left(\alpha^{*} p\right)
$$

where

$$
\alpha^{*}=\frac{1}{p}\left[\ln \left(\eta_{0}\right)+9.67\right]\left\{\left(1+\frac{p}{1.98 \times 10^{8}}\right)^{Z}-1\right\}
$$

And the pressure viscosity index is

$$
Z=\frac{\alpha_{0}}{5.1 \times 10^{-9}\left[\ln \left(\eta_{0}\right)+9.67\right]}
$$

The lubricant viscosity at atmospheric pressure $\eta_{0}$, lubricant density at atmospheric pressure $\rho_{0}$ and the pressure viscosity coefficient $\alpha_{0}$ are given in Table 1 . The density pressure relationship is ${ }^{44}$

$$
\rho=\rho_{0}\left[1+\frac{c\left(p-p_{a t m}\right)}{1+d\left(p-p_{a t m}\right)}\right]
$$

in which the constants $c$ and $d$ are $6 \times 10^{-10}$ and $1.7 \times 10^{-9}$, respectively.

The film shape is described as (Figure 5)

$$
h(x, y, t)=h_{m}(t)+h_{s}(x, y)+h_{t}(x, y)
$$




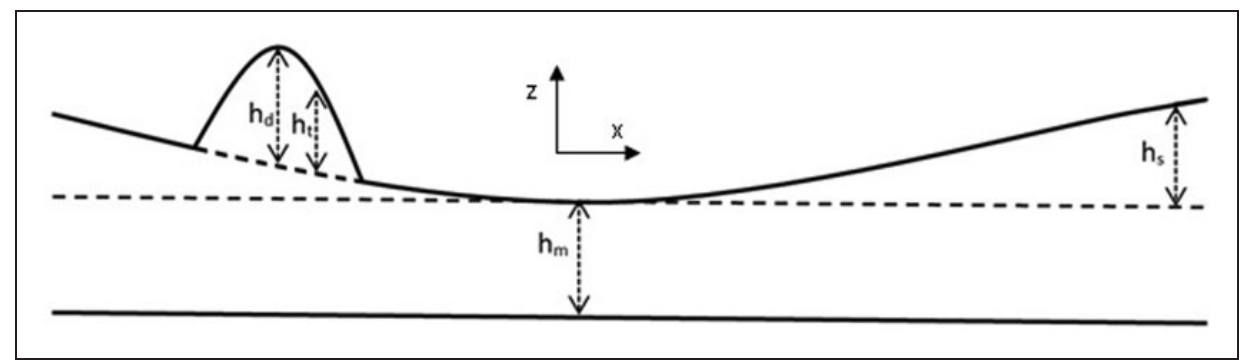

Figure 5. Film shape for rough contact with surface texture.

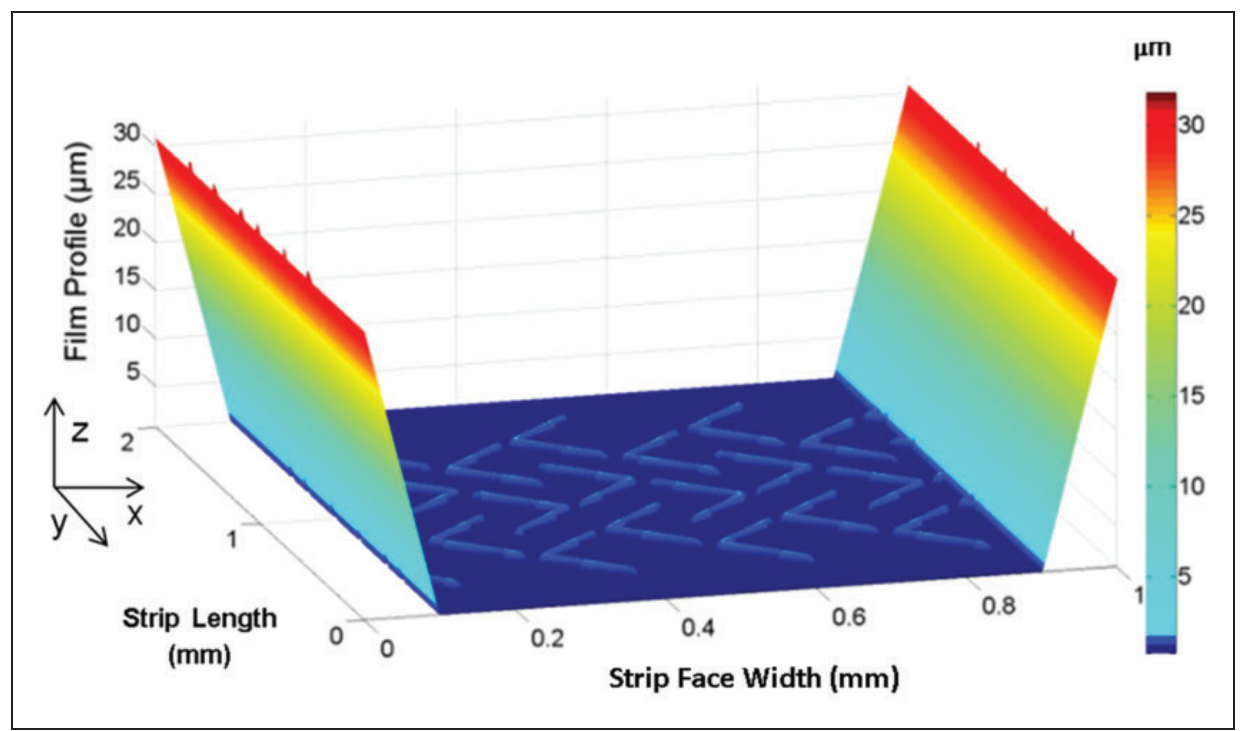

Figure 6. Film shape with chevrons.

where $h_{m}$ is the minimum film thickness, $h_{s}$ is the ring face profile and $h_{t}$ describes the amplitude of surface features; in this case the depth of the chevrons. As already noted, with relatively low applied load, no localised deflection of the contiguous solid surfaces is expected, as also noted in Akalin and Newaz ${ }^{35}$ and Mishra et al. ${ }^{36}$ The contact of the sliding strip can represent a fully circumferentially conforming piston top ring to the liner surface, when viewed as unwrapped. In this approximation the ring is assumed not to undergo any elastodynamic behaviour. In reality, Baker et al. ${ }^{45}$ have shown that in fact the top compression ring undergoes modal deformation to conform well to a right circular cylindrical liner and perform its desired sealing function. Therefore, the approximate representation made here is quite reasonable.

\section{Face profile of the sliding strip}

The strip's face-width profile $h_{s}$ is measured, and is modelled as only varying in the $x$-direction (direction of entraining motion). The axial strip profile is an important factor for the entrainment of the lubricant into the conjunction through hydrodynamic inlet wedge effect. ${ }^{6}$ Therefore, sliding rings often have profiled edges such as small relief radii or chamfers.

For the purpose of numerical analysis, the strip profile was measured using an Alicona Infinite Focus Microscope; with a measurement resolution of $1 \mathrm{~nm}$. From the measurements taken, the strip slider profile in Figure 6 is created using the following set of equations

$$
h_{s}(x)=\left\{\begin{array}{ll}
-s x+g & \text { if } x \leqslant q \\
0 & \text { if } q<x<r \\
s x-g & \text { if } x \geqslant r
\end{array}\right\}
$$

where, $s$ is the gradient of the ring profile in the $x$ direction at both ends of the ring profile, $g$ is the film profile at $x=0$ (the intercept) and $r$ and $q$ refer to the edge and flat land film shape. Figure 6 also shows the profile of laser textured chevrons.

\section{Numerical reconstruction of laser textured chevrons}

The surface features are modelled so that their inclusion angle, the perpendicular (length), width and thickness can all be readily altered. These are based on the measurements using the infinite 
focus microscope. Additionally, inter-spacing between chevrons in a row, $y$ (in the transverse direction) and the separation between rows of chevrons, $x$ (in the direction of sliding) were taken into account, as well the commencement and termination points of the textured region.

The laser surface texturing process produces a chevron with a cross-sectional profile similar to that of a parabola (Figure 3). Therefore, the chevrons were modelled with a parabolic profile as shown in Figure 7.

If $l_{c}$ is the thickness of a chevron, $h_{d}$ its depth at its centre line location and $x_{m}$ the position of the centreline of the chevron cross-sectional width, then a chevron profile can be described as

$$
\left(\frac{x-x_{m}}{l_{c} / 2}\right)^{2}+\frac{h_{t}}{h_{d}}=1
$$

\section{Contact forces}

The thin sliding strip is subjected to an applied load $F$. This force is opposed by the generated contact force contributions as a result of hydrodynamic pressures and the share of load carried by direct asperity interactions, thus

$$
W=W_{a}+W_{h}
$$

where the load carried by the lubricant film is the integral of the generated pressure distribution as

$$
W_{h}=\int_{0}^{l} \int_{0}^{b} p \mathrm{~d} x \mathrm{~d} y
$$

The share of load carried by the asperities can be written as ${ }^{46}$

$$
W_{a}=\frac{16 \sqrt{2}}{15} \pi(\zeta \kappa \sigma)^{2} \sqrt{\frac{\sigma}{\kappa}} E^{\prime} A F_{5 / 2}(\lambda)
$$

The dimensionless group $\xi \kappa \sigma$ is known as the roughness parameter, while the term $\sigma / \kappa$ is a measure of the typical asperity slope. ${ }^{6}$ These parameters are obtained through topographical measurements. The statistical function $F_{5 / 2}(\lambda)$ is introduced to match the assumed Gaussian distribution of asperities as a function of the Stribeck oil film parameter, $\lambda=h(x, y) / \sigma$. This is obtained as follows ${ }^{6}$

$$
\begin{aligned}
F_{5 / 2}(\lambda)= & \max \left\{-0.0046 \lambda^{5}+0.00574 \lambda^{4}\right. \\
& -0.2958 \lambda^{3}+0.7844 \lambda^{2} \\
& -1.0776 \lambda+0.6167,0\}
\end{aligned}
$$

Greenwood and Tripp ${ }^{46}$ model is applicable to surfaces with Gaussian distribution of asperities. For such surfaces the statistical skewness parameter $S_{s k}=0$ and the kurtosis ${ }^{30} S_{k u}=3$. Clearly, with the inclusion of chevrons on a hitherto Gaussian surface the skewness value would not remain zero. Through a series of measurements carried out on in-process wear of plateau honed cylinder liners in fired engine tests, Gore et $\mathrm{al}^{47}$ showed that for run-in cylinder liners the depth of the valleys $R_{v k}$ was almost unchanged, whilst the peakiness on the formed plateau between the grooves $\left(R_{p k}\right)$ were quickly removed, leaving a plateau height of mean roughness height of $R_{k}$. The skewness parameter for the plateau tended to zero (i.e. a Gaussian plateau height). In the case of laser etched

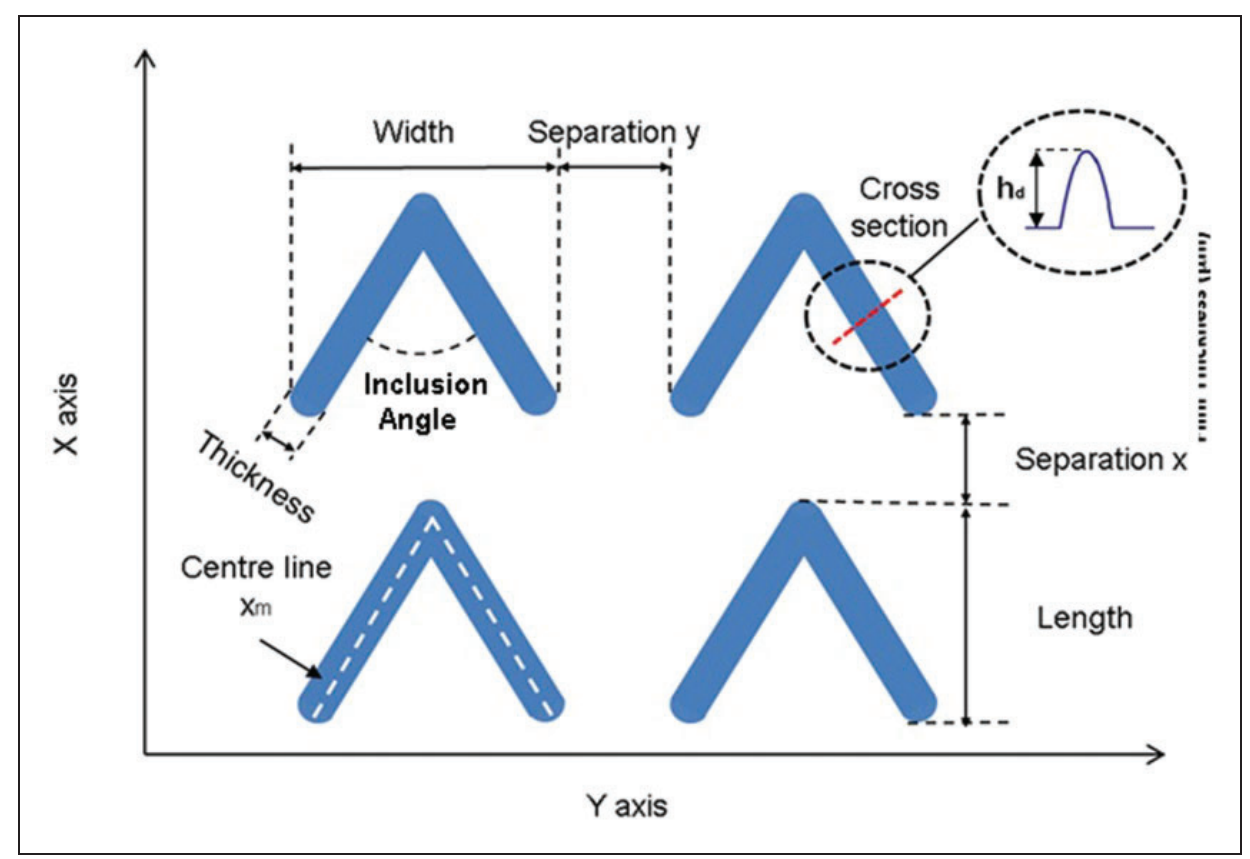

Figure 7. A schematic of a chevron-based pattern. 
plates in the current work, the chevron depth acts in a similar manner to that of Gore et al. ${ }^{47}$ engine tests of cylinder liners. No boundary interactions are expected over the chevron areas, but only on the plateaus formed between them, the roughness distribution over which may be considered to follow a Gaussian distribution. In the absence of an alternative, simple analytical method to that of Greenwood and Tripp ${ }^{46}$ and the evidence of similar representative surface by Gore et al. ${ }^{47}$ such an approach is assumed here. Later, the close agreement between the experimental measurements and the numerical predictions give further credence to the assumption made.

\section{Method of solution}

Reynolds equation is discretised using finite difference method, including density and viscosity as functions of generated pressure for the sake of completeness of the method, although the generated hydrodynamic pressures are insufficient in this instance to significantly alter the lubricant rheological state. Thus

$$
\frac{\partial \psi_{i}}{\partial x_{k}}=\left(\frac{\partial \psi_{i}}{\partial p}\right)\left(\frac{\partial p}{\partial x_{k}}\right) ; \quad\left\{\begin{array}{l}
i=1,2 \\
k=1,2
\end{array}\right.
$$

where $\psi_{1}=\rho, \psi_{2}=\eta, x_{1}=x, x_{2}=y$. After combining the above derivatives in the Reynolds equation and using central differences for the second-order pressure differentials, pressure at each computational node is obtained through the recursive relationship

$$
p_{i, j}=\frac{A_{i, j}+M_{i, j} p_{x}+N_{i, j} p_{y}-6 R_{i, j}}{2\left(\frac{1}{\Delta x^{2}}+\frac{1}{\Delta y^{2}}\right)}
$$

where $p_{x}=\frac{\partial p}{\partial x}=\frac{p_{i+1, j}-p_{i-1, j}}{2 \Delta x}$ and $p_{y}=\frac{\partial p}{\partial y}=\frac{p_{i, j+1}-p_{i, j-1}}{2 \Delta y}$. The other terms are provided in Appendix 4. Pressure at any computational node $(i, j)$ is obtained through a point successive over-relaxation (PSOR) iterative method. The pressure for each node is updated using under or over-relaxation, subscripts $n$ and $o$ denote new and old iteration steps.

$$
p_{i, j}^{n}=(1-\gamma) p_{i, j}^{o}+\gamma p_{i, j}^{n} ; \quad(0<\gamma<2)
$$

The relaxation factor $\gamma$ is problem-dependent and an optimum value which provides rapid convergence is usually obtained after some numerical tests.

\section{Convergence criteria}

A two stage convergence process is sought. The first criterion is based on the convergence of generated hydrodynamic pressures and the lubricant rheological state as

$$
E r r_{\text {pressure }}=\frac{\sum_{i=1}^{I} \sum_{j=1}^{J}\left|p_{i, j}^{n}-p_{i, j}^{0}\right|}{\sum_{i=1}^{I} \sum_{j=1}^{J} p_{i, j}^{n}} \leqslant 1 \times 10^{-5}
$$

Also

$$
\begin{aligned}
& E r r_{\text {rheological properties }} \\
& \quad=\frac{\sum_{i=1}^{I} \sum_{j=1}^{J}\left|\psi_{i, j}^{n}-\psi_{i, j}^{0}\right|}{\sum_{i=1}^{I} \sum_{j=1}^{J} \psi_{i, j}^{n}} \leqslant 1 \times 10^{-3}
\end{aligned}
$$

The second criterion is load balance for instantaneous quasi-static equilibrium, where the contact load must equate the applied load to the sliding strip

$$
\operatorname{Err}_{\text {load }}=\frac{\left|F_{r}-W\right|}{F_{r}} \leqslant 1 \times 10^{-3}
$$

If this criterion is not met, then the minimum film thickness is adjusted as

$$
h_{m}^{n}=(1+\beta \chi) h_{m}^{o}
$$

where $\chi$ is an adjusting parameter, $\chi=W-F_{r} / \max \left\{W, F_{r}\right\}$. A damping coefficient of $\beta=0.05$ is used to effect faster load convergence, whilst avoiding numerical instability.

Finally, a typical analysis cycle requires an initial guess as the nominal minimum clearance.

\section{Friction and power loss}

In the mixed regime of lubrication, anticipated in the case of contact of the sliding strip against the flat floating plate, two sources contribute to friction; viscous shear of the lubricant entrained into the conjunction and any direct interaction of counterface asperities.

At any time the viscous shear of a lubricant film $h$ can be obtained as:

$$
\vec{\tau}=\left| \pm \frac{h}{2} \vec{\nabla} p-\Delta \vec{V} \frac{\eta}{h}\right|
$$

The gradient is defined as $\vec{\nabla} \equiv(\partial / \partial x \hat{i}+\partial / \partial y \hat{j})$. The Eyring shear stress ${ }^{48}$ for the base oil used in this study is $2 \mathrm{MPa}$. The maximum shear stress calculated using equation (24) under the testing conditions reported in this paper is only $7 \mathrm{kPa}$. Thus, the base oil is subjected to Newtonian shear for this lightly loaded low sliding speed conditions

$$
f_{v}=\tau A_{v}=\tau A
$$

where $A$ is the apparent contact area. Since the area of asperity contact is usually very small, then: $A_{v}=A-A_{a}=A$. It should be noted that the asperity contact area is less than $1 \%$ of the apparent contact area. The asperity contact area for their assumed Gaussian distribution is ${ }^{46}$

$$
A_{a}=\pi^{2}(\zeta k \sigma)^{2} A F_{2}(\lambda)
$$


where 6,46

$$
\begin{array}{r}
F_{2}(\lambda)=\max \left\{-0.002 \lambda^{5}+0.028 \lambda^{4}-0.173 \lambda^{3}\right. \\
\left.+0.526 \lambda^{2}-0.804 \lambda+0.500,0\right\}
\end{array}
$$

Under the mixed regime of lubrication, boundary friction must also be taken into account.

It is assumed that boundary friction comprises two contributions; one is as the result of direct contact of asperities in the form of their adhesive junctions, which must be broken in order to sustain the sliding motion. If the pressure-induced shear strength of asperities is $\xi$, then the direct asperity friction is obtained as: $\xi W_{a}$. Secondly, a thin film of lubricant is also entrapped between the interspatial cavities of asperities. Briscoe and Evans ${ }^{49}$ assume that such diminutive films act in non-Newtonian shear, at the limiting Eyring shear stress, $\tau_{0}$, thus their frictional contribution is $\tau_{0} A_{a}$. Hence, boundary friction is obtained as

$$
f_{b}=\tau_{0} A_{a}+\xi W_{a}
$$

For a ferrous oxide layer ${ }^{50} \xi=0.17$ and for the base oil used: $\tau_{0}=2 \mathrm{MPa}$. An important point to note is that lubricants used in most applications, including in internal combustion engines include additives within the base oil, some of which are boundary active and form thin, low shear strength films adsorbed to the boundary solids. These tend to reduce the boundary shear strength at the asperity level. Description of surface adsorb films does not conform to the continuum mechanics approach of Reynolds equation. ${ }^{4,5}$ A statistical mechanics approach, including surface adsorption and elastoplastic deformation of wetted asperities is provided elsewhere. $^{51}$

Thus, the total friction is obtained as

$$
f_{t}=f_{v}+f_{b}
$$

The total power loss from the conjunction friction is

$$
P_{f}=f_{t}|\Delta U|
$$

\section{Results of numerical analysis}

Figure 8(a) and (c) shows the pressure distribution for the contact of the thin strip sliding on an un-textured

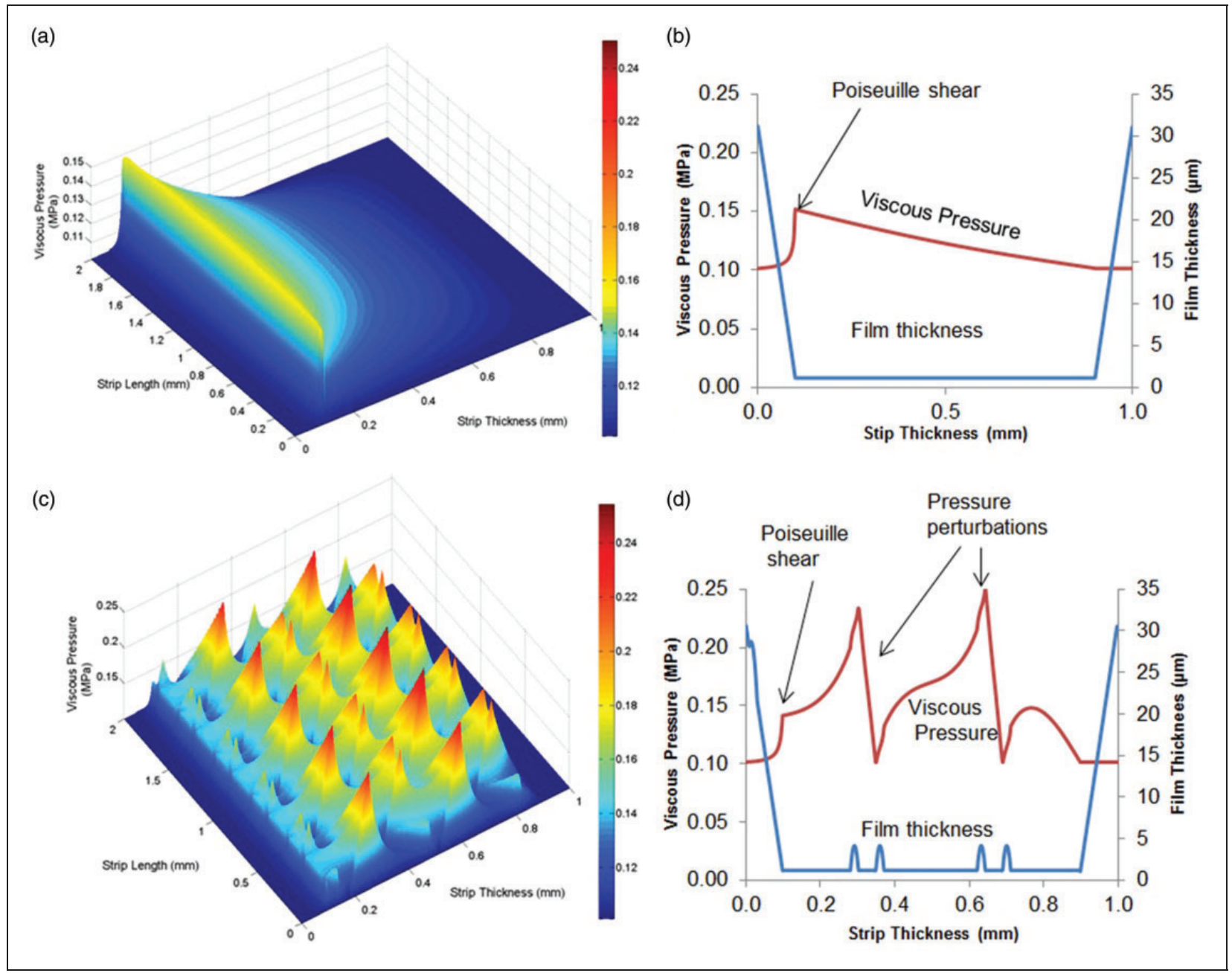

Figure 8. Pressure distribution and film shape for smooth (untextured) and textured surfaces. 
surface and that for a textured surface with chevron features, respectively. Pressure perturbations are evident in the case of the latter, with magnitudes well in excess of the average pressure of $0.15 \mathrm{MPa}$. These perturbations are as the result of micro-hydrodynamics, induced by the wedge effect at the inlet to each chevron feature as shown in Figure 8(d), which is not evident in the case of the nominally smooth plate (Figure 8(b)). The initial pressure spike at the contact inlet in both cases is caused by the pressure-induced Poiseuille shear flow with the commencement of entraining motion. There is a less pronounced Poiseuille shear at the contact entrance in the case of the textured surface on the account of a shallower pressure gradient due to a larger volume of lubricant. Note that in the case of the untextured surface, the viscous pressure falls gradually back to the atmospheric value at the diverging section of the strip as the profile of the central portion of the strip is flat and hence there would be no contribution due to any changes in the conjunctional profile as is the case for a parabolic profile. ${ }^{6}$

The results in Figure 8 confirm the enhanced loadcarrying capacity of the contact with the introduced textured features in almost the same manner as that noted for rough articular cartilage. ${ }^{6}$ The pressure distribution in Figure 8(d) is as the result of combined micro-hydrodynamics of individual chevrons as well as the effect of their collective effect. This collective effect of texture forms; chevrons or dimples, is as the result of interactions of their individual micro-hydrodynamics as noted by Brizmer et al. ${ }^{52}$ Therefore, the distribution and spatial disposition of the textures as well as the geometry of individual features play an important role in lubricant film formation, load-carrying capacity and generated friction, a parametric study of which is an important undertaking.

\section{Numerical parametric studies}

A parametric study of the chevron textures is carried out to determine the most influential geometrical and distribution parameters, which would enhance the hydrodynamic load-carrying capacity, thus reducing the chance of asperity interactions. A test matrix for the input data is shown in Table 4, listing the range of geometric parameters considered.

The first parameter considered is the chevron depth. Feature depth has been reported as a key parameter by Ryk et al. ${ }^{53}$ The thickness of chevrons is also considered, so that the reported 'optimal' heightto-width ratio reported by Ronen et al. ${ }^{11}$ can be investigated. It has also been reported by Etsion et al. ${ }^{54}$ that the texture density has a significant effect on the tribological performance of the contact. The chevron inclusion angle is also considered to be of interest for the investigation. In effect, chevrons represent a form of cross-hatched surface which is often a process of choice for cylinder liner technology. Spencer et al. ${ }^{55}$
Table 4. Test matrix for parametric study.

\begin{tabular}{llllll}
\hline $\begin{array}{l}\text { Parameter } \\
\text { test type }\end{array}$ & $\begin{array}{l}\text { Depth } \\
(\mu \mathrm{m})\end{array}$ & $\begin{array}{l}\text { Inclusion } \\
\text { angle }\left({ }^{\circ}\right)\end{array}$ & $\begin{array}{l}\text { Thickness } \\
(\mu \mathrm{m})\end{array}$ & $\begin{array}{l}\text { Pattern } \\
(\%)\end{array}$ \\
\hline Depth test & $1-9$ & 120 & 30 & $\mathrm{I}$ & 3.4 \\
Angle test & 3 & $30-120$ & 30 & $\mathrm{I}$ & $2-2.4$ \\
Thickness test & 3 & 120 & $30-100$ & $\mathrm{I}$ & $3.4-9.0$ \\
Pattern test & 3 & 120 & 30 & $1-8$ & 5.1 \\
Density test & 3 & 120 & 30 & $\mathrm{I}$ & $10-35$ \\
\hline
\end{tabular}

have shown the influence of cross-hatch angle to the horizontal (direction of side-leakage flow) to be optimum at $28^{\circ}-30^{\circ}$.

The distribution or the pattern of the chevrons was also deemed worthy of investigation. A study by Wakuda et al. ${ }^{25}$ indicated that the surface texture distribution can affect the tribological properties of the contact.

The improvement in friction for a range of the chevrons with different depths is shown in Figure 9(d). The chevron depth has a clear effect on the percentage reduction in friction. A depth of $3 \mu \mathrm{m}$ indicated the maximum predicted friction reduction. Table 4 shows that these analyses were carried out with a chevron thickness of $30 \mu \mathrm{m}$, representing a height-to-width ratio of 0.1 .

The results for the variation of chevron thickness are also shown in Figure 9(a). The chevron depth was kept at $3 \mu \mathrm{m}$ for all other analyses. Therefore, the depth-to-thickness ratio only varies in the range: $0.03-0.075$.

The effect of chevron inclusion angle is also presented in Figure 9(c). An angle of $80^{\circ}$ was found to give the greatest reduction in friction. If chevron texture is to be regarded as being analogous to the usual cross-hatch honed cylinder liner surfaces, then the equivalent cross-hatch angle (measured with respect to the direction of side leakage, $y$ ) would be $50^{\circ}$ in this case. The analysis by Spencer et al ${ }^{55}$ for the case of cross-hatched cylinders indicated an overall better performance for a cross-hatch angle of around $30^{\circ}$. However, this is dependent on the sliding speed and the depth of the grooves. Furthermore, the current analysis assumes a nominally smooth land/plateau between the chevron features, which is not the case in Spencer et al. ${ }^{55} \mathrm{~A}$ more detailed analysis, including the effect of surface roughness would be required.

As well as the individual chevron properties such as the chevron depth, thickness and inclusion angle, there are also other group-type parameters of interest such as the texture density and pattern. Group parameters are defined as properties which are dependent on a combination of two or more chevrons. The next part of the parametric study is concerned with these group parameters and their effects upon generated friction. Increasing the texture density leads to a greater improvement in friction. In applications such 


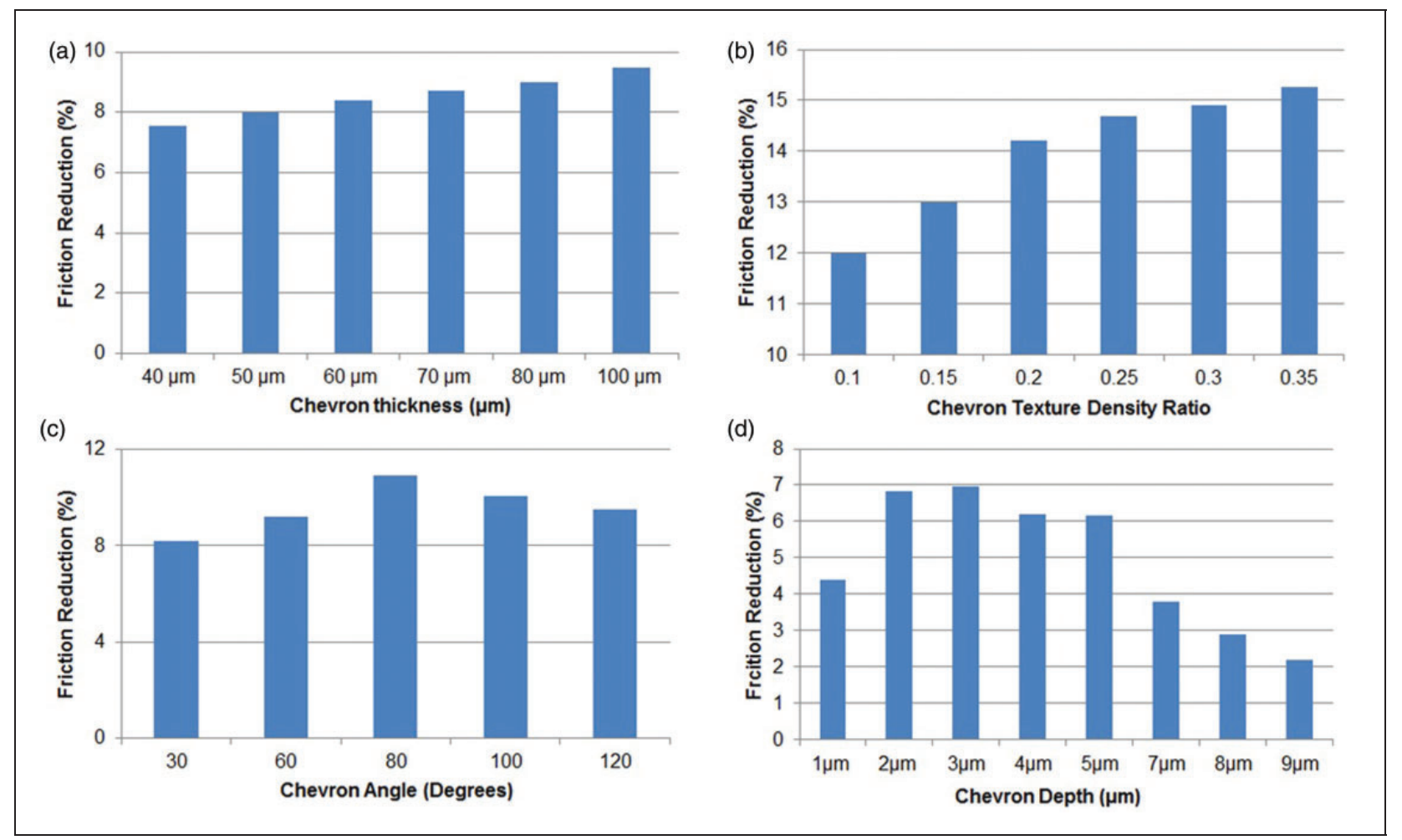

Figure 9. Results of numerical parametric studies.

as the piston compression ring-cylinder liner contact, blow-by is a real problem. Increasing the texture density could increase the amount of lubricant passage through the ring and thus contribute to blow-by, power loss or lubricant degradation. Therefore, one should be cautious when applying textures with a high density to a surface in such applications.

The results in Figure 9(b) show that chevron density has a key effect on the percentage improvement in friction. As the chevron texture density increases the generated friction is reduced as it would be expected because of a larger reservoir of lubricant entrapped. The textured density is limited by the chevron shape and size.

The pattern of the chevrons on the plate can also be varied in many ways. The range of patterns to model can of course be almost in-exhaustive. However, to fit within the parametric study it was decided to vary the orientation of the chevrons with respect to the direction of sliding as well as any row of chevrons' staggered with respect to a preceding row by half of a chevron's length. Figure 10 shows eight different patterns modelled. Pattern 1 corresponds to that presented by Costa and Hutchings. ${ }^{9}$ As can be seen, all patterns comprising individual chevrons of identical geometrical attributes promote micro-hydrodynamic effect as already noted and described in the case of Figure 8(c), but not in a similar overall manner under the same operating conditions (load and sliding speed). The position of the strip width of $1 \mathrm{~mm}$ is also shown in all the figures. Three particular patterns; identified as 1, 4 and 8 in Figure 10 provide an improvement in friction in comparison with the others (Figure 11), although the difference in friction between all the patterns is less than $1 \%$. This small difference, however, may be regarded as quite significant if it can be attained for applications such as compression ring-to-cylinder liner system. Pattern 8 replicates the counter-pose of successive rows of chevrons, with a preceding row facing the direction of sliding motion whilst the following row opposes the same. The philosophy behind these counter-posing rows of chevrons is that the one ahead of the sliding strip would form a convex meniscus directing the entrainment flow to the centre of the contact, whilst the other at the rear of the contact would contain the otherwise outward wake flow due to any side leakage. This pattern was used with curvilinear chevrons by Howell-Smith et al., ${ }^{30}$ where a full numerical analysis and engine test data showed $2-4 \%$ friction reduction over a range of engine running conditions.

\section{Experimental results}

With the results of the aforementioned parametric analysis, it was decided to create four types of chevron textures. The chevron parameters chosen for this purpose are: a chevron thickness of $30 \mu \mathrm{m}$ (as the variation on the generated friction was caused by increasing density rather than any other effect, see section 'Numerical parametric studies'). Furthermore, by keeping the laser beam width for a chevron leg thickness of $30 \mu \mathrm{m}$ the production time of the samples was significantly reduced. A chevron 


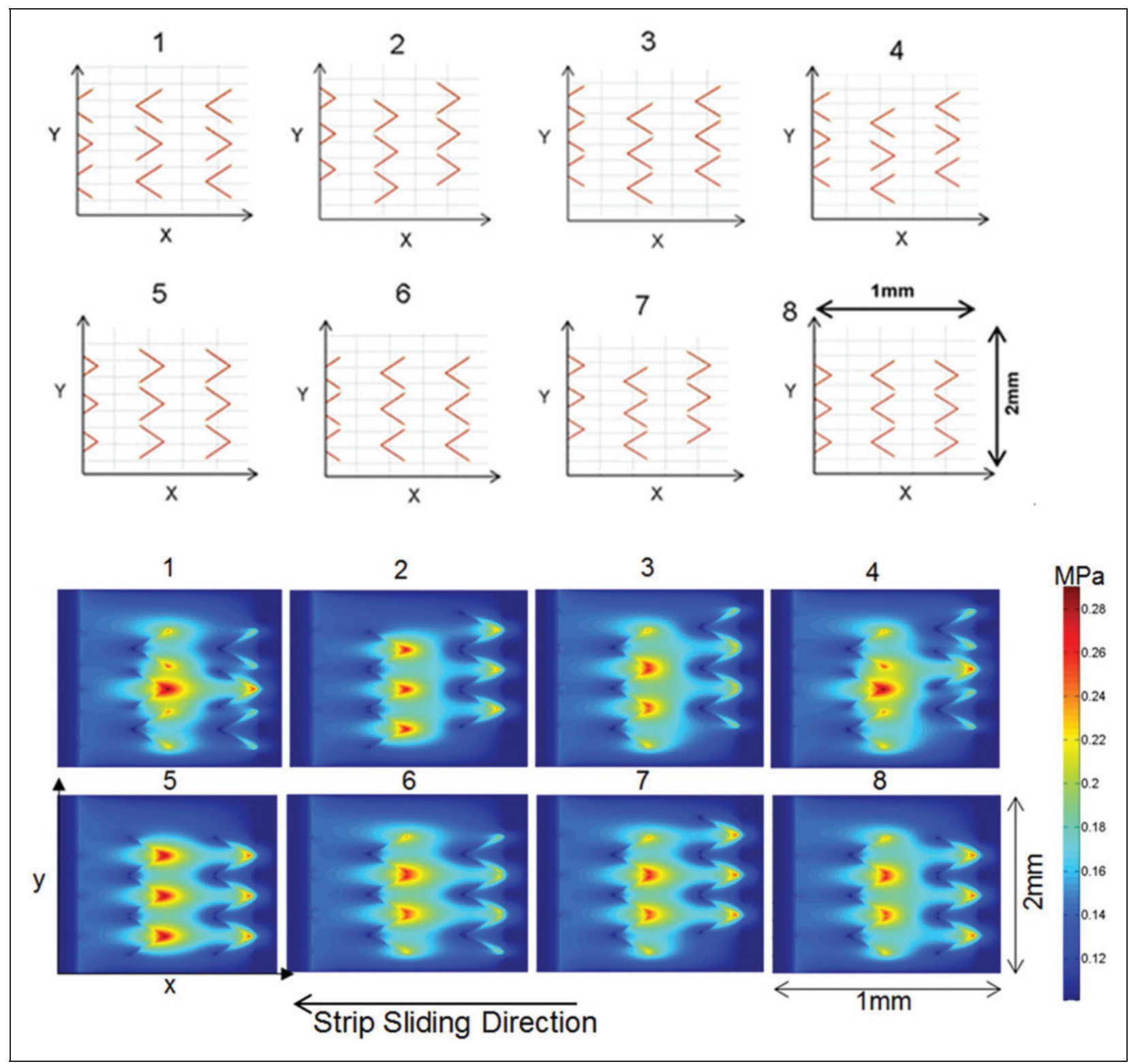

Figure 10. Chevron textured patterns and micro-hydrodynamic effect.

depth of $3 \mu \mathrm{m}$ was chosen to adhere to the aforementioned height-to-width ratio of 0.1 , noted to be an optimum ratio by Etsion and Sher. ${ }^{28}$

Although the results of parametric study for the chevron inclusion angle indicated an optimum values of $80^{\circ}$ (representing a $50^{\circ}$ equivalent crosshatch angle), it was decided to opt for an inclusion angle of $120^{\circ}$. The main reason for this was that the ultimate motivation for this research is to use the eventual configuration from the current study for use in advanced cylinder liner technology of high performing engines. Additionally, it has been noted in practice that features with shallower crosshatch angle perform better in engine applications which, as noted above, has been confirmed by the numerical predictions in Spencer et al. ${ }^{55}$ Different distributions of chevrons are used (Table 5, Figure 12).
Numerical simulation of these various patterns yields the percentage reductions in friction with respect to an un-textured nominally smooth surface.

The new chevron patterns show reduction in friction of around $4 \%$ with respect to the original pattern based on that of Costa and Hutchings. ${ }^{9}$

All the new patterns and that in Costa and Hutchings ${ }^{9}$ were manufactured and subjected to testing (see Appendix 2 for the test protocol) using the precision slider rig, described in section 'Reciprocating sliding contacts'.

The initial step was to validate the numerical analysis, thus gain confidence in the result of parametric analysis. This comparison is shown in Figure 14(a). The region containing the chevron textures is highlighted in the figure. A reduction in predicted as well as measured friction is noted as the sliding strip enters the textured region. A sharper drop in friction is noted 


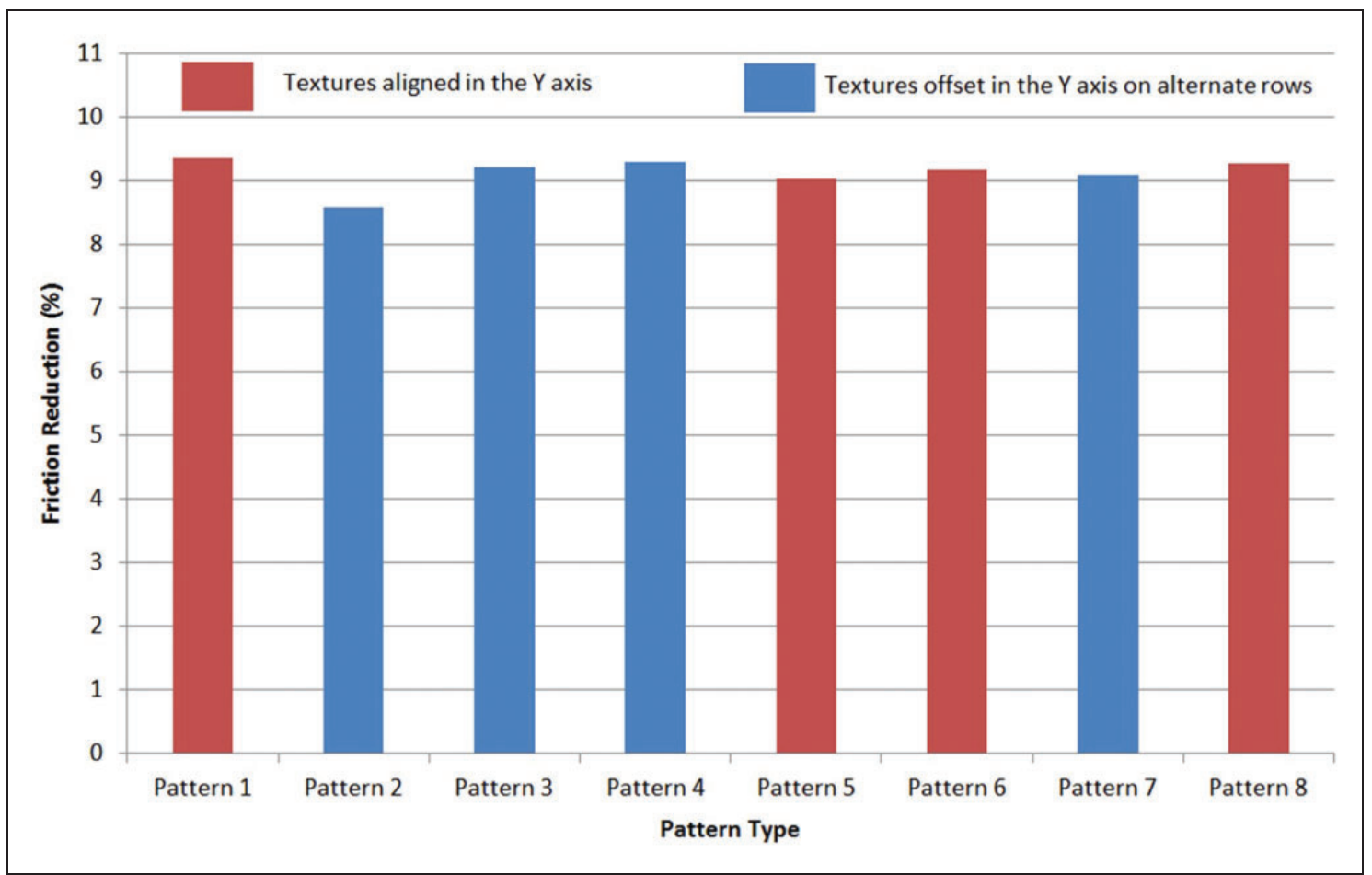

Figure II. Predictive studies for various textured patterns in Figure 10.

Table 5. Chevron parameters.

\begin{tabular}{|c|c|c|c|c|c|c|c|}
\hline Chevron type & Depth $(\mu \mathrm{m})$ & Angle $\left(^{\circ}\right)$ & Thickness $(\mu \mathrm{m})$ & Pattern & Density (\%) & Width $(\mu \mathrm{m})$ & Length $(\mu \mathrm{m})$ \\
\hline Costa $^{9}$ & 5 & 120 & 30 & I & 7.0 & 450 & 130 \\
\hline Chevron A & 3 & 120 & 30 & 8 & 11.5 & 370 & 106 \\
\hline Chevron B & 3 & 120 & 30 & 8 & 9.1 & 370 & 106 \\
\hline Chevron C & 3 & 120 & 30 & 8 & 12.7 & 290 & 84 \\
\hline Chevron D & 3 & 120 & 30 & 8 & 14.0 & 200 & 57 \\
\hline
\end{tabular}

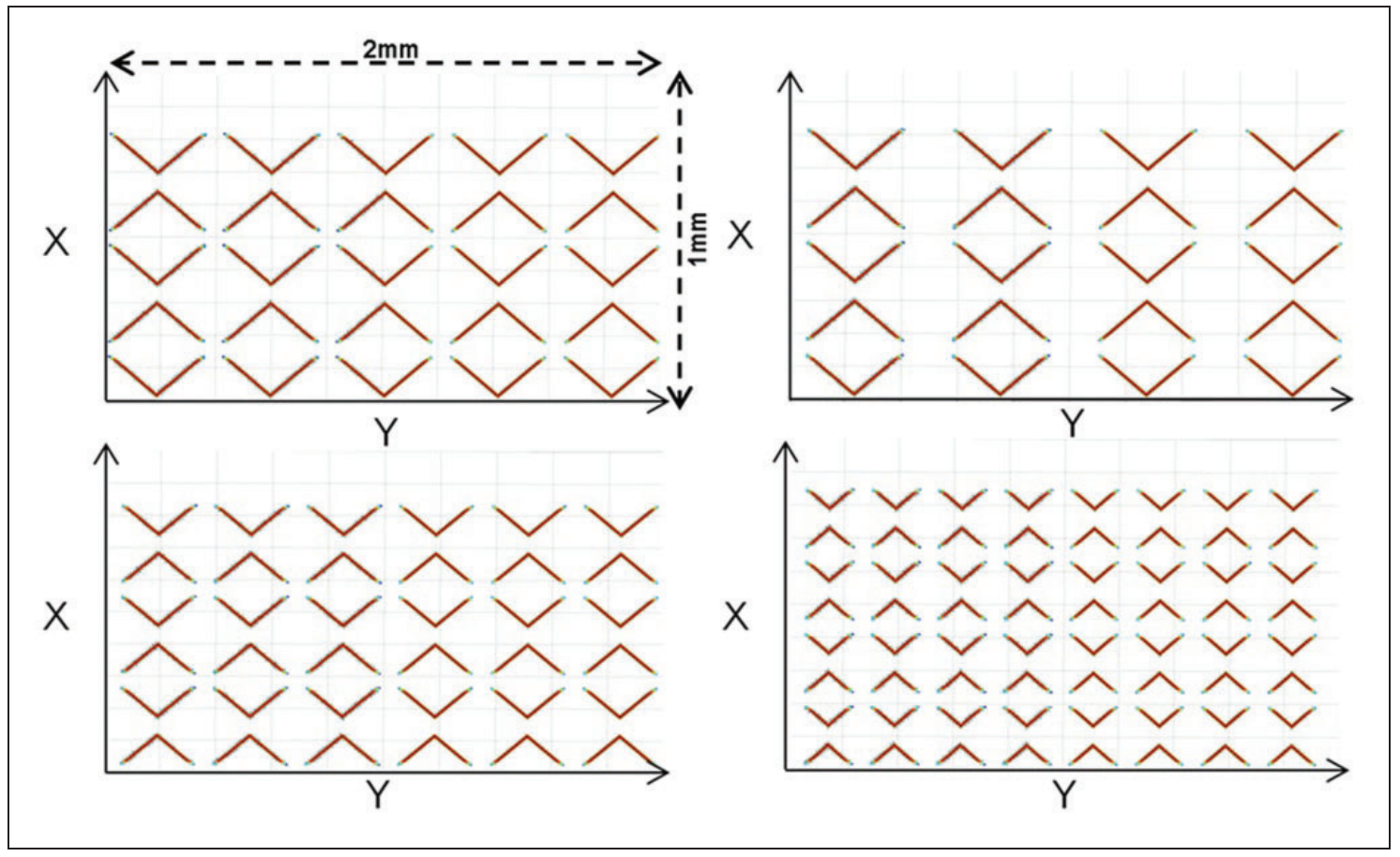

Figure 12. Distribution of chevrons left to right, top row: Patterns $A$ and $B$, bottom row: Patterns $C$ and $D$. 


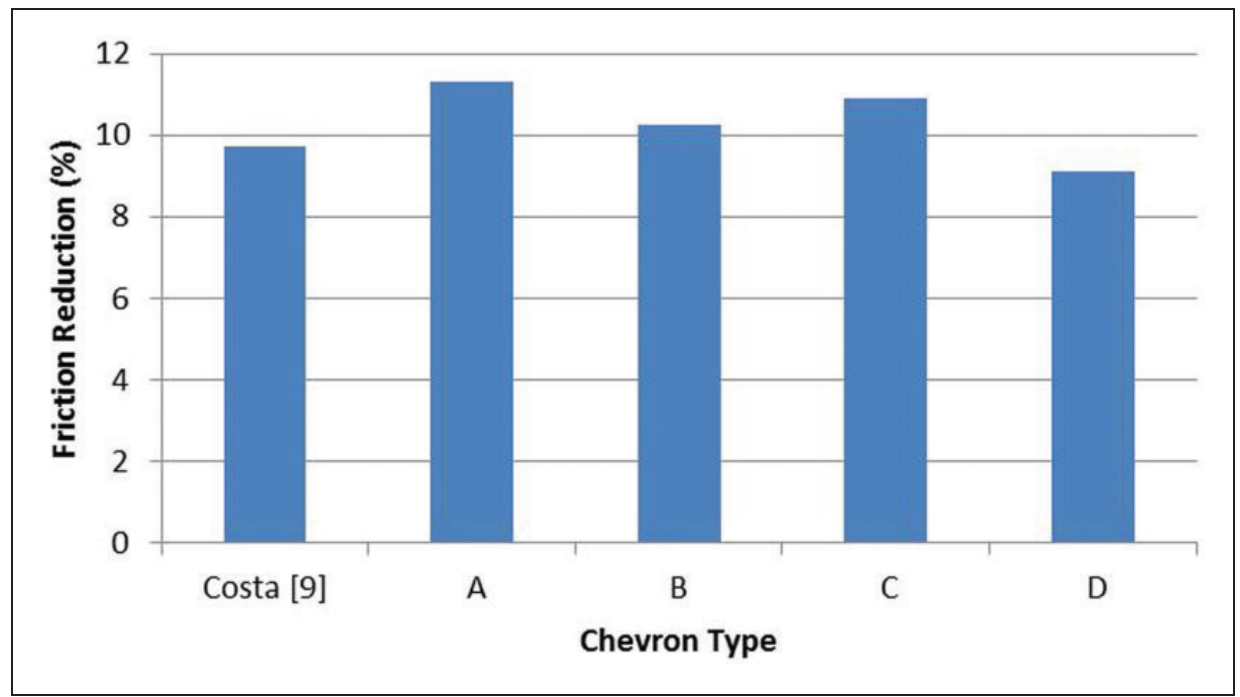

Figure 13. Predicted reduction in friction with the patterns made for testing.

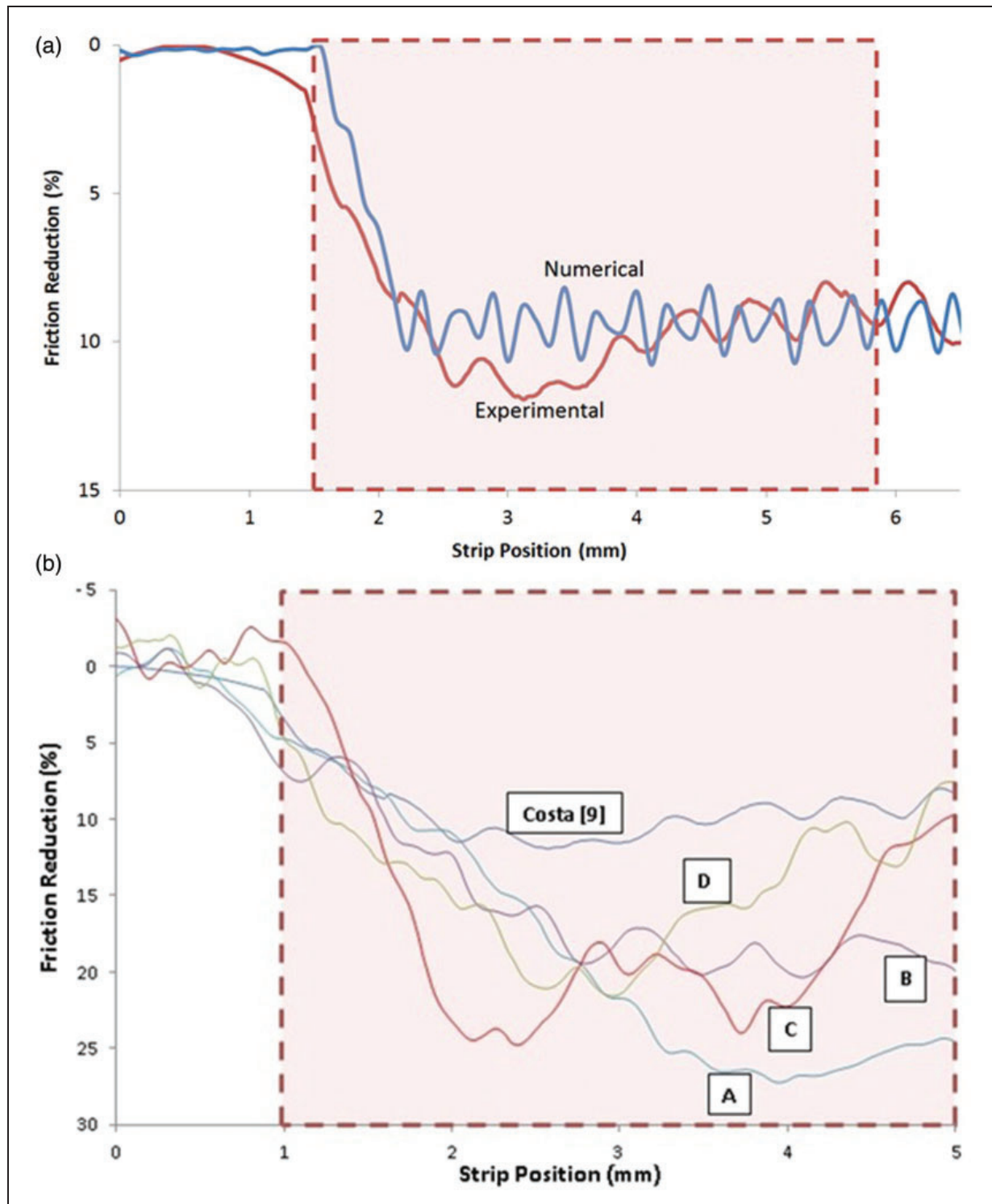

Figure 14. Prototype testing of the various manufactured laser etched chevron patterns in Figure I2: (a) Validation of numerical predictions; (b) Bench marking of various patterns. 
in the case of measured results at the onset of textured region. This indicates that in practice a lesser Poiseuille shear exists at contact inlet. This means that there must be a greater volume of lubricant in the inlet region of the contact than the just flooded condition assumed in the numerical analysis. Nevertheless, an overall good agreement is noted between the numerical prediction and that measured.

The next step was to measure friction for the various patterns in Table 5. The results are shown in terms of friction reduction with respect to an untextured surface in Figure 14(b). All textured patterns show significant reduction in friction relative to an untreated surface. There is a difference in an initial drop in friction between different textured patterns at the onset of entry into the textured region. As already noted, this is mainly due to Poiseuille shear on the account of encountered inlet pressure gradient in the presence of identical measured sliding speed (thus almost the same nominal Couette shear) and load (see also 'Concluding remarks').

\section{Concluding remarks}

It is shown through numerical analysis and precision measurement that for low sliding motion textured surfaces of suitable geometry, pattern and distribution can induce micro-hydrodynamic pressure perturbations, thus enhance lubricant film thickness. This leads to a reduction in generated conjunctional friction. It is also shown that various texture geometrical attributes and distribution can be used to 'optimise' the prevailing regime of lubrication, thus reducing friction. It is clear that a choice of these pertinent parameters depends on the application in mind and the operating conditions such as sliding speed and conjunctional load. Therefore, 'optimisation' would be application dependent.

In particular, the study shows that lubricant retention in the created micro-reservoirs as well as pressure perturbations at the inlet conjunction can result in differing extent of effective micro-wedge effect, which is also crucially dependent on the supply of the lubricant at the contact inlet. In practice, such as in light-to-medium loaded reversal region of piston-cylinder liner contact in transition from compression to power stroke, supply of inlet meniscus to the contact cannot be controlled on the account of high surface temperatures in the combustion chamber. There is also modal deformation of contiguous surfaces, such as the piston compression ring and the cylinder liner ${ }^{45}$ which deviate from their ideal circumferential conformity. Therefore, unlike mechanical seals and rings where entrance wedge geometry can be controlled to a certain extent as well as a fully flooded inlet, optimisation to the degree of minutiae in cylinder technology would be cost inefficient so long as any significant reduction can be achieved in line with the cost of manufacture. The study shows that texturing has the potential to meet the practical requirements, but as shown by Howell-Smith et al. ${ }^{30}$ not to the extent indicated under controlled and relatively ideal laboratory conditions.

\section{Acknowledgements}

The authors thank the EPSRC and all the partner organisations in the Encyclopaedic project, in particular in this instance to Capricorn Automotive.

\section{Conflict of interest}

None declared.

\section{Funding}

The authors wish to express their gratitude to the Engineering and Physical Sciences Research Council (EPSRC) for the sponsorship of this research under the Encyclopaedic Program Grant (www.Encyclopaedic.org).

\section{References}

1. Amontons G. De la resistance causée dans les machines. Mem Acad Roy 1699; 275-282.

2. Euler L. Sur le frottement des corps solides. Memoires de l'Academie des sciences de Berlin 1750; 4: 122-132.

3. Coulomb CA. Theorie des machines simples. Mem Math Phys Acad Sci 1785; 10: 161-331.

4. Petrov NP. Friction in machines and the effect of the lubricant. Inzhenerno Zhurnal St. Petersburg 1883; 1: 71-140.

5. Hardy WB and Doubleday I. Boundary lubrication. The paraffin series. Proc Roy Soc Lond Ser A 1922; 100(707): 550-574.

6. Gohar R and Rahnejat H. Fundamentals of tribology. London: Imperial College Press, 2008.

7. Chong WWF, Teodorescu M and Rahnejat H. Physiochemical hydrodynamic mechanism underlying the formation of thin adsorbed boundary films. Faraday Discuss 2012; 156: 123-136.

8. Teodorescu M and Rahnejat H. Dry and wet nano-scale impact dynamics of rough surfaces with or without a self-assembled monolayer. Proc IMechE, Part N: J Nanoengineering and Nanosystems 2008; 221: 49-58.

9. Costa HL and Hutchings IM. Hydrodynamic lubrication of textured steel surfaces under reciprocating sliding conditions. Tribol Int 2007; 40(8): 1227-1238.

10. Etsion I and Burstein L. Improving tribological performance of piston rings by partial surface texturing. Tribol Trans 1996; 39(3): 677-683.

11. Ronen A, Etsion I and Kligerman Y. Friction-reducing surface-texturing in reciprocating automotive components. Tribol Trans 2001; 44(3): 359-366.

12. Rahmani R, Shirvani A and Shirvani H. Optimization of partially textured parallel thrust bearings with square-shaped micro-dimples. Tribol Trans 2007; 50(3): 401-406.

13. Rahmani R. An Investigation into analysis and optimisation of textured slider bearings with application in piston ring/cylinder liner contact. $\mathrm{PhD}$ Thesis, Anglia Ruskin University, 2008.

14. Balakrishnan $\mathrm{S}$, Howell-Smith $\mathrm{S}$ and Rahnejat $\mathrm{H}$. Investigation of reciprocating conformal contact of piston skirt-to-surface modified cylinder liner in high 
performance engines. Proc IMechE, Part C: $J$ Mechanical Engineering Science 2005; 219(11): 1235-1247.

15. Etsion I. Surface texturing for in-cylinder friction reduction. In: H Rahnejat (ed.) Tribology and dynamics of engine and powertrain. Cambridge, UK: Woodhead Publishing, 2010, pp.458-467.

16. Rahnejat H, Balakrishnan S, King PD, et al. In-cylinder friction reduction using a surface finish optimization technique. Proc IMechE, Part D: J Automobile Engineering 2006; 220(9): 1309-1318.

17. Yu XQ, He S and Cai RL. Frictional characteristics of mechanical seals with a laser-textured seal face. $J$ Mater Process Technol 2002; 129(1): 463-466.

18. Pettersson U and Jacobson S. Textured surfaces for improved lubrication at high pressure and low sliding speed of roller/piston in hydraulic motors. Tribol Int 2007; 40(2): 355-359.

19. Wang X, Kato K, Adachi K, et al. The effect of laser texturing of $\mathrm{SiC}$ surface on the critical load for the transition of water lubrication mode from hydrodynamic to mixed. Tribol Int 2001; 34(10): 703-711.

20. Wang X, Kato K, Adachi K, et al. Loads carrying capacity map for the surface texture design of $\mathrm{SiC}$ thrust bearing sliding in water. Tribol Int 2003; 36(3): 189-197.

21. Erdemir A. Review of engineered tribological interfaces for improved boundary lubrication. Tribol Int 2005; 38(3): 249-256.

22. Schneider YG. Formation of surfaces with uniform micropatterns on precision machine and instrument parts. Precision Eng 1984; 6: 219-225.

23. Křupka I and Hartl M. The effect of surface texturing on thin EHD lubrication films. Tribol Int 2007; 40(7): $1100-1110$.

24. Morris NJ, Rahnejat H and Rahmani R. Tribology of partial pad journal bearings with textured surfaces. In: $3 \mathrm{rd}$ European conference on tribology (ECOTRIB), Vienna, Austria, 7-9 June 2011, Österreichische Tribologische Gesellschaft (The Austrian Tribology Society).

25. Wakuda M, Yamauchi Y, Kanzaki S, et al. Effect of surface texturing on friction reduction between ceramic and steel materials under lubricated sliding contact. Wear 2003; 254(3): 356-363.

26. Pettersson U and Jacobson S. Influence of surface texture on boundary lubricated sliding contacts. Tribol Int 2003; 36(11): 857-864.

27. Etsion I. State of the art in laser surface texturing. Trans ASME Ser F: J Tribol 2005; 127(1): 248-253.

28. Etsion I and Sher E. Improving fuel efficiency with laser surface textured piston rings. Tribol Int 2009; 42(4): $542-547$.

29. Ryk G and Etsion I. Testing piston rings in partial laser surface texturing for friction reduction. Wear 2006; 261(7): 792-796.

30. Howell-Smith S, Rahnejat H, King PD, et al. Reducing in-cylinder parasitic losses through surface modification and coating. Proc. IMechE, Part D: J Automobile Engineering 2014; 228: 391-402.

31. Balakrishnan $\mathrm{S}$ and Rahnejat $\mathrm{H}$. Isothermal transient analysis of piston skirt-to-cylinder wall contacts under combined axial, lateral and tilting motion. $J$ Phys $D$ : Appl Phys 2005; 38(5): 787-799.
32. Furuhama $\mathrm{S}$ and Sasaki S. New device for the measurement of piston frictional forces in small engines. SAE paper 831284, 1983.

33. Gore M, Theaker M, Howell-Smith S, et al. Direct measurement of piston friction of internal-combustion engines using the floating-liner principle. Proc IMechE, Part D: J Automobile Engineering 2014; 228(3): 344-354.

34. Chong WWF and De la Cruz M. Elastoplastic contact of rough surfaces: A line contact model for boundary regime of lubrication. Meccanica. Epub ahead of print January 2014. DOI: 10.1007/s11012013-9861-1.

35. Akalin $\mathrm{O}$ and Newaz GM. Piston ring-cylinder bore friction modeling in mixed lubrication regime, part I: Analytical results. Trans ASME J Tribol 2001; 123: 211-218.

36. Mishra PC, Balakrishnan S and Rahnejat H. Tribology of compression ring-to-cylinder contact at reversal. Proc IMechE, Part J: J Engineering Tribology 2008; 222: 815-826.

37. Swift HW. The stability of lubricating films in journal bearings. J Inst Civil Eng 1932; 233(1): 267-288.

38. Stieber W. Dus Schwimmlager. Verein Deutscher. Berlin: Ingenieurre, 1933.

39. Elrod HG. A cavitation algorithm. J Lubric Technol 1981; 103(3): 350-354.

40. Ausas R, Ragot P, Leiva J, et al. The impact of the cavitation model in the Analysis of micro-textured lubricated journal bearings. Trans ASME $J$ Tribol 2009; 129: 868-875.

41. Shahmohamadi H, Rahmani R, Rahnejat $H$, et al. Thermo-mixed hydrodynamics of piston compression ring conjunction. Tribol Lett 2013; 51(3): 323-340.

42. Arcoumanis C, Duszynski M, Flora $\mathrm{H}$, et al. Development of a piston-ring lubrication test-rig and investigation of boundary conditions for modelling lubricant film properties. SAE paper 952468, 1996.

43. Roelands CJA. Correlation aspects of the viscositytemperature-pressure relationships of lubricating oils. Druk VRB Kleine der A3-4 Groningen, 1966.

44. Dowson D and Higginson GR. A numerical solution to the elastohydrodynamic problem. J Mech Eng Sci 1959; 10(Part 1): 6-15.

45. Baker CE, Theodossiades S, Rahnejat $\mathrm{H}$, et al. Influence of in-plane dynamics of thin compression rings on friction in internal combustion engines. Trans ASME J Eng Gas Turb Power 2012; 134(9): 092801.

46. Greenwood JA and Tripp JH. The contact of two nominally flat rough surfaces. Proc IMechE: J Mechanical Engineering Science 1970-1971; 185(1): 625-633.

47. Gore M, Perera M, Styles G, et al. Wear characteristics of advanced honed and cross-hatched coated cylinder liners. In: Proceedings of the 66th annual meeting and exhibition of the STLE, 2011, p. 73.

48. Eyring H. Viscosity, plasticity and diffusion as examples of reaction rates. J Chem Phys 1936; 4: 283-291.

49. Briscoe BJ and Evans DCB. The shear properties of Langmuir-Blodgett layers. Proc Roy Soc Ser A Math Phys Sci 1982; 380: 389-407.

50. Teodorescu M, Balakrishnan $\mathrm{S}$ and Rahnejat $\mathrm{H}$. Integrated tribological analysis within a multi-physics approach to system dynamics. Tribol Interf Eng Ser 2005; 48: 725-737. 
51. Chong WWF, Teodorescu $M$ and Rahnejat $H$ Nanoscale elastoplastic adhesion of wet asperities. Proc IMechE, Part J: J Engineering Tribology 2013; 227: 996-1010.

52. Brizmer V, Kligerman Y and Etsion I. A laser surface textured parallel thrust bearing. Tribol Trans 2003; 46(3): 397-403.

53. Ryk G, Kligerman Y and Etsion I. Experimental investigation of laser surface texturing for reciprocating automotive components. Tribol Trans 2002; 45(4): 444-449.

54. Etsion I, Halperin G, Brizmer V, et al. Experimental investigation of laser surface textured parallel thrust bearings. Tribol Lett 2004; 17(2): 295-300.

55. Spencer A, Almqvist A and Larsson R. A numerical model to investigate the effect of honing angle on the hydrodynamic lubrication between a combustion engine piston ring and cylinder liner. Proc IMechE, Part J: $J$ Engineering Tribology 2011; 225(7): 683-689.

56. Rahnejat H. Multi-body dynamics: Vehicles, machines and mechanisms. Bury St Edmunds, UK: Professional Engineering Publishers, 1998.

\section{Appendix I}

\section{Notation}

$A$

$A_{a}$

$A_{v}$

b

E'

$f_{b}$

$f_{t}$

$f_{v}$

$F$

$F_{2}, F_{\frac{5}{2}} \quad$ statistical functions

$F_{r}$

$g$

$h_{m}$

$h_{d}$

$h_{t}$

$h_{s}$

$h$

$l$

$l_{c}$

$\ell$

$m$

$p$

$p_{c}$

$p_{\text {atm }}$

$p_{\text {in }}$

$p_{\text {out }}$

$P_{f}$

$P_{f b}$

$P_{f v}$ acceleration

apparent contact area

asperity contact area

viscous contact area

sliding strip face-width

reduced (effective) elastic modulus of

the contacting pair

boundary friction

total friction

viscous friction

force

load on sliding strip

constant

minimum film thickness

maximum texture depth

texture profile

profile of sliding strip

film thickness

length of sliding strip

thickness of chevron leg

connecting rod length

mass

hydrodynamic pressure

cavitation pressure

atmospheric pressure

inlet pressure

outlet pressure

total frictional power loss

frictional power loss due to boundary interactions

frictional power loss due to lubricant viscous shear $q, r$

$r_{c}$

$R_{a}$

$R_{k}$

$R_{p k}$

$R_{q}$

$R_{v k}$

$S$

$S_{s k}$

$S_{k u}$

$t$

$\vec{U}$

V
$W$

$W$
$W_{a}$

$W_{h}$

$x$

$x_{c}$

$x_{m}$

$y$

Z

$\alpha^{*}$

$\alpha_{0}$

$\beta$

$\chi$

$\Delta U$

$\eta_{0}$

$\eta$

$\gamma$

$\kappa$

$\lambda$

$\omega$

$\varphi$

$\rho$

$\rho_{0}$

$\sigma$

$\tau_{0}$

$\xi$

$\zeta$ constants

crank-pin radius

average height of roughness

average core roughness on the plateau

average peak heights on the unworn

plateau

root mean squared roughness

average valley depth

constant

skewness of the roughness frequency

distribution

kurtosis

time

speed of entraining motion

velocity vector

contact load

load share of the asperities

load share of the lubricant film

direction along the strip face-width

(direction of entraining motion)

film rupture boundary

centre line of the chevron

direction along the strip length (direc-

tion of side leakage)

viscosity-pressure index

viscosity-pressure coefficient

atmospheric viscosity-pressure

coefficient

numerical damping factor

adjusting parameter

sliding velocity

lubricant dynamic viscosity at atmo-

spheric pressure and ambient

temperature

lubricant dynamic viscosity

relaxation factor

average radius of curvature of asperity summits

Stribeck's oil film parameter

crankshaft speed

crank angle

lubricant density

lubricant density at atmospheric

pressure

root mean square roughness of the

counterfaces

shear stress

Eyring shear stress

coefficient of boundary shear strength of a surface

asperity density per unit contact area

\section{Appendix 2}

\section{Test protocol}

Repeatability of testing conditions is crucial in a benchmarking exercise, comprising different textured 
configurations. For this purpose a test protocol was devised. The load cells were calibrated before each set of tests. The contacting surface topography of the strip and the floating plate specimen were measured using an Alicona Infinite Focus microscope with a nominal measurement resolution of the order of wavelength of light propagation. The strip and the floating plate specimen were then mounted onto the slider test rig, care was taken to ensure proper alignment was attained for all tests. A controlled volume of base oil $(0.15 \mathrm{~mL})$ was applied to the flat liner plate using a hypodermic syringe. No boundary active species are present in the base oil as these would adsorb to the conjunctional surfaces and cannot be easily and reliably removed, thus affecting repeatable testing conditions. An initial running-in period was allowed prior to each test. Each test consisted of a single pass over the textured area. A settling time of $5 \mathrm{~min}$ between successive runs were allowed in order to allow any rise in temperature to be dissipated. For each textured case 15 runs were carried out. After each test the surfaces of the strip and the floating plate were again measured.

\section{Appendix 3}

\section{Load intensity}

The aim of the analysis and testing with the slider rig is to develop texture patterns and geometry for ultimate use in piston-cylinder system at and in the vicinity of the top dead centre reversal. Therefore, load and sliding speed variation used in the current analysis should be representative of conditions encountered for the intended application. Figure 15 shows the operating conditions for the Honda CRF 450 single cylinder motocross motorsport normally aspirated engine under fired condition and the engine speed of $2000 \mathrm{r} / \mathrm{min}$ with partial application of throttle (yielding a torque of $30 \mathrm{Nm}$ ) on a test bed. The engine and test bed arrangement are described by Gore et al. ${ }^{33}$ Figure 4 shows the nominal calculated piston sliding speed, using ${ }^{56}$

$$
\Delta U(\varphi)=r_{c} \omega \sin \varphi\left(1+\cos \varphi\left[\left(\frac{l}{r}\right)^{2}-\sin ^{2} \varphi\right]^{1 / 2}\right)
$$

The figure shows that the part of engine cycle where the sliding speed is representative of the slider bearing kinematics is around the piston reversals, $\pm 10^{\circ}$ about the reversal position. The contact load variation is also in the figure, indicating that load intensity (per unit area of contact of piston compression ring) is in the range shown in Table 6 . The load intensity for the thin slider strip in the slider rig is also stated in Table 6. Therefore, the load intensity for the studied conditions is quite representative of the reversal region for engine conditions at low piston sliding speed and at partial

Table 6. Load intensity comparison of the slider test rig and Honda CRF450R engine.

\begin{tabular}{lllc}
\hline & $\begin{array}{l}\text { Load at } \\
\text { reversal }(\mathrm{N})\end{array}$ & $\begin{array}{l}\text { Ring } \\
\text { length }(\mathrm{m})\end{array}$ & $\begin{array}{l}\text { Load } \\
\text { intensity }(\mathrm{N} / \mathrm{m})\end{array}$ \\
\hline $\begin{array}{l}\text { Honda CRF } \\
\text { Engine }\end{array}$ & $140-230$ & 0.27 & $500-852$ \\
$\begin{array}{c}\text { Slider test rig } \\
\text { L }\end{array}$ & 12.4 & 0.03 & 413 \\
\hline
\end{tabular}

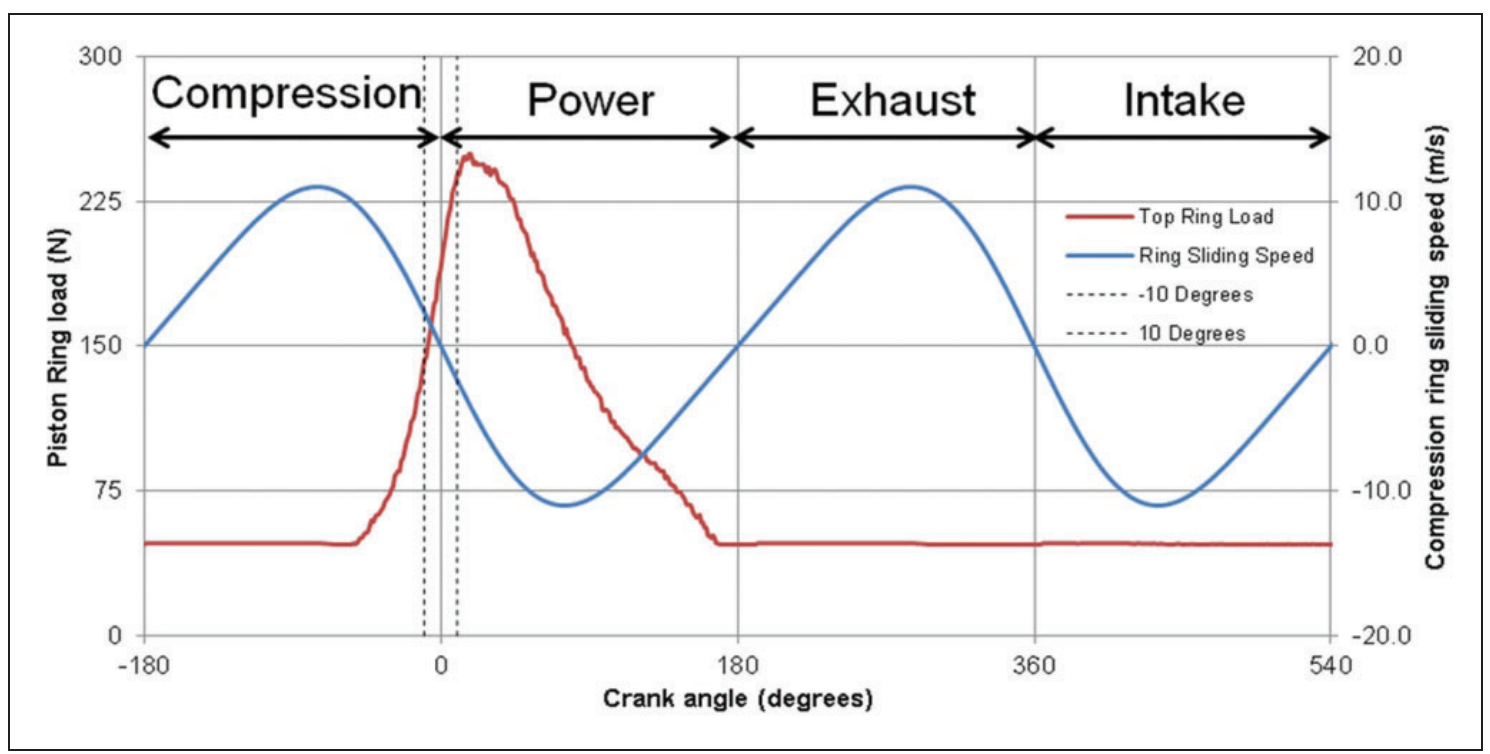

Figure I5. Honda CRF450R Compression ring sliding speed and load at $2000 \mathrm{r} / \mathrm{min}$ and $30 \mathrm{Nm}$ (partial throttle). 
throttle, where worst tribological conditions are often noted.

\section{Appendix 4}

\section{Discretised terms}

The following discretised terms are used in equation (18)

$$
\begin{aligned}
& A_{i, j}=\frac{p_{i-1, j}+p_{i+1, j}}{\Delta x^{2}}+\frac{p_{i, j-1}+p_{i, j+1}}{\Delta y^{2}} \\
& M_{i, j}=\left[\frac{1}{\rho} \frac{\partial \rho}{\partial x}-\frac{1}{\eta} \frac{\partial \eta}{\partial x}+3 \frac{1}{h} \frac{\partial h}{\partial x}\right]_{i, j}
\end{aligned}
$$

$$
\begin{aligned}
N_{i, j}= & {\left[\frac{1}{\rho} \frac{\partial \rho}{\partial y}-\frac{1}{\eta} \frac{\partial \eta}{\partial y}+3 \frac{1}{h} \frac{\partial h}{\partial y}\right]_{i, j} } \\
R_{i, j}= & \left\{\frac { \eta } { h ^ { 2 } } \left[\left(\Delta U\left(\frac{1}{\rho} \frac{\partial \rho}{\partial x}+\frac{1}{h} \frac{\partial h}{\partial x}\right)\right)\right.\right. \\
& \left.\left.+2\left(\frac{1}{\rho} \frac{\partial \rho}{\partial t}+\frac{1}{h} \frac{\partial h}{\partial t}\right)\right]\right\}_{i, j}
\end{aligned}
$$

The side-leakage due to Poiseuille flow is taken into account. There is no sliding in the lateral $y$-direction. Hence, the side-leakage due to Couette flow is ignored. 